OPEN ACCESS

Edited by:

Carmel Cefai,

University of Malta, Malta

Reviewed by:

Juko Ando,

Keio University, Japan

Darko Roviš,

University of Rijeka, Croatia

*Correspondence:

Jesús de la Fuente

jdlfuente@unav.es

Specialty section:

This article was submitted to

Psychopathology

a section of the journal

Frontiers in Psychiatry

Received: 29 August 2020 Accepted: 08 June 2021 Published: 08 July 2021

Citation: de la Fuente J, González-Torres MC, Artuch-Garde R, Vera-Martínez MM, Martínez-Vicente JM and

Peralta-Sánchez FJ (2021) Resilience as a Buffering Variable Between the Big Five Components and Factors and

Symptoms of Academic Stress at

University,

Front. Psychiatry 12:600240.

doi: 10.3389/fpsyt.2021.600240

\section{Resilience as a Buffering Variable Between the Big Five Components and Factors and Symptoms of Academic Stress at University}

\author{
Jesús de la Fuente ${ }^{1,2 *}$, María Carmen González-Torres ${ }^{1}$, Raquel Artuch-Garde ${ }^{3}$, \\ Manuel Mariano Vera-Martínez ${ }^{4}$, Jose Manuel Martínez-Vicente ${ }^{2}$ and \\ Francisco Javier Peralta-Sánchez ${ }^{2}$ \\ ${ }^{1}$ School of Education and Psychology, University of Navarra, Pamplona, Spain, ${ }^{2}$ School of Psychology, University of Almería, \\ Almería, Spain, ${ }^{3}$ Department of Health Sciences, School of Psychology, Public University of Navarra, Pamplona, Spain, \\ ${ }^{4}$ School of Psychology, University of Granada, Granada, Spain
}

The aim of this cross-sectional study was to establish predictive relationships of the Big Five personality factors (according to their self-regulatory level), together with resilience (proactive and reactive factors), for factors and symptoms of academic stress related to teaching and learning in the University context. A total of 405 female undergraduate students were selected, and completed questionnaires that had been previously validated in Spanish University students (Big Five personality factors, resilience, and academic stress symptoms and factors). A linear, ex-post facto design was used, including linear regression, Structural Equation Modeling (SEM), and mediational analyses. Specific linear regression showed the expected gradation: that self-regulatory personality factors (conscientiousness, extraversion) were positive linear predictors of proactive resilience, as well as significant negative predictors of stress factors and symptoms of academic stress; while the non-regulatory personality factors (openness to experience, agreeableness) showed little relationship. By contrast, the dysregulatory personality factor (neuroticism) was a negative predictor of proactive resilience, a positive predictor of reactive resilience, and positively predicted academic stress factors in the teaching and learning process, as well as stress symptoms. SEM general analysis showed that personality factors positively predicted resilience, and resilience negatively predicted factors and symptoms of academic stress. Specific mediational model analysis, with each personality factor, confirmed the different mediating relationships that appeared in the linear regression analyses. These results are discussed from the perspective of promoting resilience and healthy personalities in the University context. Implications for addressing academic stress at University are discussed.

Keywords: Big Five model, resilience, stress and factor symptoms, SEM model, university 


\section{INTRODUCTION}

Stress in the University context is a natural phenomenon (1) and has been a common problem for college students in every era (2). Nonetheless, the college environment seems to be increasingly stressful in recent decades $(3,4)$ and the experience of perceived stress, anxiety, and feeling overwhelmed is widespread among college students, including those who succeed, as documented by different surveys $(5,6)$ and diverse publications (7-11). Reddy et al. (12) claim that this has become a grave reality to the point of becoming a "career stopper."

Students are subjected to many different sources of stress, especially academic stressors, which are well-documented in the literature $(3,13,14)$. The evaluative processes that are involved in one's subjective experience of stress (15) are affected by contextual and psychosocial factors $(8,16-18)$.

The way we react to stress varies greatly between individuals, and the students need develop personal resources to successfully progress through higher education, despite its constant challenges (19). Recent years have seen growing interest in these resources what are called non-cognitive variables-also known as personal skills, personal qualities, character traits, psychosocial skills, and soft skills (20-23) - for their important impact on educational achievement, success in the job market, career and life success, and well-being $(24,25)$. Among the non-cognitive skills that may increase vulnerability to stress, or, constitute protective resources for coping, two important constructs have been emphasized, and will be addressed in this study: personality traits (BF model) and resilience (19). In research on stress at University, particularly from the standpoint of health sciences, certain personality traits are considered critical non-cognitive variables that make up a resilient personality, able to manage stress successfully (19). However, from the Vulnerability- stress model or diathesisstress model (26), individuals may possess a pre-disposition toward certain disorders, as is the case with neuroticism, where individuals have the tendency to feel overwhelmed by stress. On the other hand, certain qualities linked to resilience can be cultivated; these qualities protect against stress and strengthen one's resistance (27).

The current study seeks to establish whether the BF traits and Resilience may be significant predictors of students' stress factors and symptoms. Another important objective is to examine the role of Resilience in mediating between the $\mathrm{BF}$ traits and stress factors and responses. To date, there has been little analysis of this role in the University context (2830).

\section{Academic Stress in the University Context: Teaching-Learning Factors and Symptoms}

Stress is a complex phenomenon and many theoretical models have been proposed to explain its etiology. "The transactional theory of stress and coping, developed by Lazarus and Folkman, has been particularly instrumental in shaping stress and coping research over the past five decades" [(31), p. 351]. According to their model (15), individuals are constantly evaluating the stimuli in their environment, and this evaluation generates emotions. Stimuli that are considered threatening, challenging or harmful result in distress, and coping strategies are then activated to manage emotions or to directly address the stressor itself. From this perspective, stress is defined as exposure to stimuli that are appraised as harmful, threatening, or challenging, exceeding the individual's capacity to cope [(31); p. 352].

The study of academic stress at University, as a factor that is detrimental to psychological health or emotional wellbeing, is a highly current research topic $(10,32,33)$. In the University context, numerous potential factors of stress have been documented and categorized, such as academics, the learning environment, campus culture, interpersonal and personal issues $(9,34)$.

\section{Academic Stress Factors From the Teaching and Learning Process}

Academic stress factors themselves can be classified into three general groups: (1) those related to performance assessment; (2) those related to a heavy workload, and (3) other conditions of the teaching-learning process, such as social relationships (teacherstudent and peer relationships), the teaching methodology and different organizational components (inadequacy of study plans, scheduling problems, overlapping programs, low student participation in management and decision-making, overcrowding, etc.) (35-37). Deane and Song (38), in a study that described eleven potential situations that generate stress and stress symptoms, found that the situations most predictive of chronic stress were class participation, required assignments and test taking. Bob et al. (39), in a sample of medical students, found that the top stressors were exams, falling behind in the learning schedule, a large amount of content to be learned, heavy workload, and lack of time to review what had been learned.

\section{Academic Stress Symptoms}

The stress response refers to the physiological, emotional or behavioral manifestations triggered by stressors (40). An acute stressor can trigger various physiological responses (rapid heartbeat, blood pressure, increased respiratory rate and corticosteroid levels, sweating, trembling, headaches, weight loss or gain, body aches, sleep quality issues). It can also affect the subjective experience in relation to cognitive reactions (perceived stress, negative thoughts, worry, sense of uncontrollability) and negative affect (irritability, agitation, fear, anxiety, guilt) (41) as well as generate behavioral responses (crying, abuse of self and others, smoking) $(12,42-44)$.

Previous research has shown that high levels of stress are associated with problems of physical health (45), ability to self-regulate (10) poor adjustment to college (46) and poor achievement $(47,48)$, involvement in unhealthy behaviors (7), depression (49), reduced well-being $(33,50)$ and less life satisfaction (51). 


\section{Personality: Big Five Model}

The Big Five (BF) personality traits, also known as the Five Factor Model (FFM) and the OCEAN Model (52), represents the most commonly used personality framework in current psychological literature. Although not universally accepted $(52,53)$, there is general agreement in the prior research on personality that the $\mathrm{BF}$ taxonomy describes the basic personality dimensions that have a substantial genetic basis (54). A great deal of empirical support has shown its universality across genders and widely differing contexts $(55,56)$.

The Big Five personality domains are: Openness $(\mathrm{O})$, Conscientiousness (C), Extraversion (E), Agreeableness (A) and Neuroticism (N) (53). Openness implies the tendency to be imaginative, curious, flexible and insightful. Conscientiousness has to do with individual differences in the manner of focusing on tasks and bringing them to completion; four facets of $\mathrm{C}$ consistently appear in many research studies: orderliness, industriousness, responsibility and self-control. Several non-cognitive constructs widely used in education are very similar to $C$, specifically, grit, time management, motivation, self-regulation, performance/mastery goals, and mindset. Extraversion describes the tendency to be outgoing, assertive and energetic and to show positive emotionality. Agreeableness has to do with being friendly, cooperative and generous, altruistic, modest, compassionate. However, Neuroticism (vs. emotional stability) implies the tendency to show anxiety, worry, negative emotionality, vulnerability, selfconsciousness, physiological reactivity to stress, and behavioral inhibition $(57,58)$.

Recent research in the University context shows that $C$ is the most closely related factor to academic performance; it encourages intrinsic academic motivation, prevents procrastination, and predicts high achievement (52, 59, 60). Schneider and Preckel's (61) systematic review of 38 metaanalyses found that, among 16 personality variables related to academic achievement, Conscientiousness showed the largest absolute effect size in predicting academic performance.

In adulthood as well, empirical studies show an association between personality traits and mental well-being. Kokko et al. (62), in their review, indicate that Neuroticism is linked most closely (and negatively) to different aspects of emotional wellbeing, including happiness, life satisfaction, affectivity, and quality of life. Steel et al. (63), in their meta-analysis of 347 samples, found that the Big Five personality traits played a very important role in emotional well-being, accounting for 40 to 60 per cent of its variance.

\section{The Graded Sequence of Self-Regulation in the Big Five Factors}

Recent research has attempted to establish the possibility of a general, transdiagnostic $p$ factor, referring to the lack of self-regulation of goal pursuit (64). In a complementary approach, the theoretical model of $S R$ vs. ER Theory (65) has hypothesized the existence of a continuum of self-regulatory, non-regulatory and dysregulatory behaviors in persons. This theory has contributed recent evidence for three claims: (1) students' levels of behavior self-regulation (high-medium-low) determine corresponding levels in several affective-motivational variables, such as engagement, resilience, and stress responses (66); (2) these regulation levels (high-medium-low) are interdependent with self-regulation/non-regulation/dysregulation behaviors, respectively, and health behaviors (67); (3) regulation levels have also been found in association with personality factors (68). For these reasons, specifically, it proposes a self-regulatory ordered sequence of personality components, from greater to lesser levels of self-regulation behavior, namely: Conscientiousness and Extraversion (selfregulatory components), Openness to Experience and Agreeability (non-regulatory components), and Neuroticism (dysregulatory component). The first two would be associated with a greater self-regulatory component (consistent pattern of proactive self-regulation behaviors, especially prominent in $\mathrm{C}$ ), the next two would be non-regulatory in nature (not consistently proactive, more reactive to the regulatory input of the context), and finally neuroticism, with a dysregulatory nature (consistent pattern of self-induced lack of self-regulation). In this regard, evidence has been presented with reference to a possible gradation of the Big Five model factors, based on relations between each component and its accompanying level of self-regulation $(68,69)$.

\section{Resilience}

Most researchers agree on the general definition of resilience as the ability to withstand adversity and recover from stress and negative experiences (70). Expanding on this definition, it can be said that resilience is also the ability to advance and grow in response to difficulties and challenges, that is, to find strength through adversity (71). Resilience is not limited to people with traumatic experiences or minority groups, it appears to be generally beneficial for study progress and for dealing with the typical challenges of University contexts (19).

Prior evidence points to resilience as a key skill for students (72), positively associated with academic engagement, academic persistence (4), mental health, well-being (73), and self-regulation $(74,75)$.

\section{Reactive and Proactive Components of Resilience}

Recent research has suggested the existence of two types of dimensions or types of factors that make up resilience, based on the CD-RISC scale (76), that is, reactive and proactive components of resilience. On one hand, there are the behavioral factors of resilience pertaining to endurance in the face of adverse conditions (reactive factors); on the other hand is the ability to bounce back and produce changes in the conditions that caused the adverse situation (proactive factors). In the first case, stress management skills and spirituality behaviors have been shown to predict emotion-focused coping strategies; in the second case, perceived competence, the ability to adapt to change and perceived control (self-regulation) have been shown to predict problem-focused strategies. Consequently, the two dimensions are complementary and necessary, although only the proactive factors would pertain to self-regulatory behavior (76). 


\section{Relationships Between the Big Five, Resilience, and Perceived Stress (Factors and Symptoms) \\ $\mathrm{BF}$ and Resilience}

Earlier research has identified a link between all five dimensions of personality and a person's ability to bounce back. In his study, Grossman (77) analyzed if the utility of resilience as a construct to predict certain criteria (measures of physical health, mental health, and well-being) is greater than that of established classical predictors, such as personality traits (BF model). Generally speaking, their results lent support to the hypothesis that general resilience was positively correlated (at least moderately) with all the BF traits. Extraversion showed the lowest correlation (0.48) and Conscientiousness showed the highest (0.64). Agreeableness showed only a moderate to low correlation with general resilience (0.40) at the 95\% confidence interval. The Grossman metaanalysis suggest that resilience overlaps substantially with bigfive prersonality traits and offer limited utility above personality in predicting health or well-being outcomes. In another metaanalysis (78), results also indicate specifically that resilience is positively related to Extraversion, Openness, Agreeableness, Emotional stability and Conscientiousness (close to 0.40) and negatively to Neuroticism $(-0.46)$. One of the most frequently used scales in these studies is the CD-RISC (79).

The sphere of health sciences is where much attention has been given to relations between resilience and the Big Five $(80,81)$. The conceptual model of medical student well-being (82) points to personality and temperament factors as fundamental to resilience (83). Recent findings also showed that all resilience factors were positively correlated with the personality profiles of well-adjusted individuals. Significant, positive relations were found between dimensions of resilience and personality traits $\mathrm{E}$, $\mathrm{O}, \mathrm{A}$, and $\mathrm{C}$; and negative relations were found with neuroticism $(19,84,85)$.

The traits most closely related to resilience were Extraversion, Conscientiousness and Neuroticism $(86,87)$. In the face of challenges, Conscientious students were able to make structured action plans, thereby building resilience and enabling them to progress in their studies (19). Pendergast (88) points to the strong relationship between Conscientiousness and Resilience as something to be expected, since $\mathrm{C}$ in college students may buffer against stress; but he also notes that this strong relationship appears when is used the CD-RISC scale, so it is possible that there is certain overlap between the two constructs. In fact, certain items that address the tenacity factor of CD-RISC may be measuring some aspect of Conscientiousness. On the other hand, Extraversion and also Agreeableness are associated with good social skills that encourage cooperation and social support that is an important protector of resilience (19).

In general, prior research may be said to show that resilient students possess a repertory of personality traits (particularly $\mathrm{C}$ and E) and coping styles (problem-focused) that act as internal protective factors, allowing them to better adapt to difficulties and stress (19).

\section{BF and Perceived Stress}

Research shows that people with different personality traits manifest different reactions to stress, which in turn affect their adjustment at University. There is substantial evidence about the $\mathrm{N}$ factor is the main predictor of high levels of subjective stress experience; less is known about how the other four factors relate to stress, and findings are less consistent $(13,43)$. For some time, there was little analysis of how all the Big Five factors were related to stress. Such studies are now increasing (14), including recent papers that examine the Big Five alongside the biological and physiological correlates of stress (43).

Recent research generally corroborates these findings, with certain qualifications. Xin et al. (43) indicate that N, E and $\mathrm{O}$ are important variables associated with the stress response, and that different dimensions of personality are associated with different aspects of the stress response. Their data indicate that higher Neuroticism predicted the physiological stress response (heartbeat and cortisol activation), a bigger drop in positive affect and lower subjective control capacity. They also indicated that individuals with greater Extraversion showed less cortisol activation to stress, and a good, resilient psychological response, with less increase in negative affect. A higher score in Openness was also associated with less cortisol response to stress. However, they point to certain inconsistencies between studies that can be attributed to factors like the subjects' demographic variables, the studies analyze different stressors, they use different measurements of the stress response, and there are issues of scientific bias. Soliemanifar et al. (89), as well as Xin et al. (43), have also analyzed the causal link between BF dimensions and biological aspects (cardiovascular and endocrine response to stress); they consider that the $\mathrm{BF}$ model provides a psychobiological typology of stress reactivity.

The connection between basic personality factors of Neuroticism, Extraversion, and Conscientiousness, stress experience and coping (18), seems well-established. Certain studies indicate that $\mathrm{O}$ and $\mathrm{A}$ have weaker or null association with stress (43). However, results about relationship between $\mathrm{C}$ and stress are still inconsistent. Certain studies have found that students with high levels of Conscientiousnness are less resistant to stress (13).

In general, the literature recognizes the role of personality traits in academic stress (90), academic performance (91) and coping (58). High neuroticism pre-disposes students to stress, making them more vulnerable. Extraversion, Conscientiousness and also Agreeableness can act as protective factors under stressful conditions. Thus, we can assume that a student with a high level of Neuroticism will consider a stressful task to be a threat (the demands of the stressor are too high when compared to the coping resources), and will increase worry about one's academic skills, negative emotional response, fear of failure or fear of poor performance. On the other hand, students with high levels of E and C (moderate level) will probably assess the stressful task as a challenge, will present active coping, support seeking, avoidance of interpersonal conflict, high motivation and feelings of competence that favor good task performance. 


\section{Resilience and Perceived Academic Stress}

Data on the role of resilience in protecting against perceived stress in undergraduate students are still limited (1), but there are some significant findings in support. Pidgeon et al. (92), in a study with an international sample of University students, found that students with low levels of resilience reported significantly lower levels of perceived social support, connectedness on campus and higher levels of psychological anxiety, compared to University students with high levels of resilience Hernandez et al. (47) also found that higher levels of academic stress were associated with less ability to bounce back. In this study, the group classified as not resilient had higher stress scores, lower self-efficacy and slightly lower academic achievement than the group classified as resilient. Pidgeon and Pickett (93), with a sample of University students with high and low levels of resilience, reported that students in the low resilience group experienced significantly lower levels of mindfulness, higher levels of psychological distress, more limited use of adaptive coping, and greater use of maladaptive coping, in comparison to students with high levels of resilience $(46,94,95)$, in 4-year longitudinal studies with University students examine multiple aspects of psychosocial adjustment: (a) psychological functioning (selfesteem and psychological distress, that is, depression, anxiety and stress), (b) cognitive-affective strategies (including active and avoidant emotional coping), and (c) social well-being (specifically social support from friends) with the purpose of identifying change patterns of risk and resilience. Their results indicate that adjustment over the 4 years at University did not change in linear fashion. Student adjustment generally worsens across the first 2 years followed by some improvement in the last two, although only self-esteem and active emotional coping were completely recovered in women, and only the latter in men.

\section{BF, Resilience, and Perceived Academic Stress}

Resilience and vulnerability to stressors depend on age, sex, intelligence, and many other personality characteristics. LecicTosevski et al. (96) indicate that the relationship between personality and stress has an impact on four important aspects: (1) choice or avoidance of settings that are associated with specific stressful factors, challenges or benefits, (2) the way one interprets a stressful situation and assesses one's own skills and abilities for adopting a proactive attitude and behavior to either confront or avoid it, (3) intensity of one's response to a stressor, and (4) coping strategies used by the individual facing a stressful situation.

Today there is a growing interest in understanding the relations between resilience, personality traits and stress (28). However, there are relatively few studies that analyze the mediational role of resilience between the Big Five and stress responses at University (30).

Some have analyzed the mediational role of resilience between personality and happiness (97) or depressive symptoms (29). For their part, Sarrionandia et al. (1) have analyzed resilience as a mediator of emotional intelligence and perceived stress. Backman et al. (19) have studied the role of the Big Five personality dimensions and Resilience in students' achievement and study progress. Their results show that four of the five dimensions of the BF model, specifically Openness, Conscientiousness,
Emotional Stability and Extraversion, were related to Resilience, and Resilience in turn resulted in better study progress. Their results of the mediation analyses also show that introducing resilience does not decrease the predictive validity of the Big Five. On the other hand, they found that Openness was negatively related to study progress, while positively related to resilience. The results of how Neuroticism relates to study progress were not clear. A significant relationship between emotional stability and study progress was not supported, but they found that emotional stability can help foster study progress through student's ability to bounce back.

The study by Shi et al. (30) is one of the few to examine the relationship between personality traits (BF) and anxiety symptoms among medical students and the first to study the mediational role of resilience in this relationship. Their results indicate that $\mathrm{A}, \mathrm{C}$ and $\mathrm{O}$ were negatively associated with anxiety while $\mathrm{N}$ was positively associated. They found that resilience works as a mediator of the relationships between $\mathrm{A}, \mathrm{C}, \mathrm{O}$ and anxiety symptoms. The authors conclude that identifying individuals at risk and implementing intervention strategies focused on personality traits and resilience can be an effective strategy to prevent and reduce anxiety symptoms.

\section{Present Study: Aims and Hypotheses}

Despite ample prior evidence on the constructs of the BF model and Resilience, no specific evaluation has been made of predictive relationships of the personality factors (according to their regulatory nature) for resilient behavior (in its reactive and proactive components). Nor has the specific mediating role of resilience been analyzed in its relation to academic stress factors from the teaching-learning process, and to symptoms of academic stress. Therefore, the aim of this study was to establish these predictive relations. The following affirmations were hypothesized:

\section{Hypothesis 1}

The more regulatory factors of the $\mathrm{BF}$ model ( $\mathrm{C}$ and $\mathrm{E}$ ) will significantly and positively predict total resilience, as well as proactive factors of resilience (perceived competence, adaptation to change, and perceived control); the non-regulatory factors of the $\mathrm{BF}$ model $(\mathrm{O}, \mathrm{A})$ will not be predictive of the proactive factors but will be more predictive of reactive factors of resilience, such as stress management and spirituality; finally, the dysregulatory factor of the $\mathrm{BF}(\mathrm{N})$ will prove to be a significant, negative predictor of total resilience and of its reactive factors. This predictive scheme will be maintained in regard to the factors and symptoms of academic stress; thus, while $\mathrm{C}$ and $\mathrm{E}$ will negatively predict the factors and symptoms of academic stress, factors $\mathrm{O}$ and $\mathrm{A}$ will have a neutral relationship and factor $\mathrm{N}$ will predict them positively.

\section{Hypothesis 2}

The proactive factors of resilience (perceived competence, adaptation to change and perceived control) will significantly, negatively predict stress factors and symptoms; however, reactive factors of resilience (endurance of stress and spirituality) will be non-significant predictors of such stress factors and symptoms. 


\section{Hypothesis 3}

Stress factors from the process of teaching and learning (especially the latter) will be the strongest predictors, positively and significantly, of stress symptoms in students.

\section{Hypothesis 4}

The general structural prediction model will show that the different personality factors, in conjunction with the different resilience factors, will be significant, negative predictors of stress factors and symptoms. In the case of the different $\mathrm{BF}$ and resilience factors, there will be corresponding indirect effects, similar to those referenced (positive, neutral or negative) in the stress factors and symptoms.

\section{Hypothesis 5}

The specific mediational models for each $\mathrm{BF}$ factor will significantly show a positive mediational value of resilience for predicting stress factors and symptoms in students, based on whether the personality factors are regulatory $(\mathrm{C}, \mathrm{E})$, nonregulatory $(\mathrm{O}, \mathrm{A})$, or dysregulatory $(\mathrm{N})$.

\section{METHODS}

\section{Participants}

The study sample contained an initial 665 undergraduate students selected from two universities in Spain. These students were pursuing degrees in Psychology, Primary Education, and Educational Psychology; $85.5 \%$ were women and $14.5 \%$ were men. After confirming significant gender differences in the variables, we limited our sample to the 405 female students. Age range was 19-25, with an average age of 21.33 years. The study design was incidental and non-randomized. The Guidance Department at each University invited teacher participation, and the teachers invited their own students to participate on an anonymous, voluntary basis. Each course (subject) was considered one specific teaching-learning process; questionnaires were completed online for each subject.

\section{Instruments}

The Big Five Questionnaire, BFQ-N (98), based on Barbaranelli et al. (99). The adaptation used in this study was for young University students (32). Confirmatory Factor Analysis (CFA) reproduced a five-factor structure corresponding to the Big Five Model. Results showed adequate psychometric properties and acceptable fit indices. The second-order confirmatory model showed good fit $[$ Chi-square $=38.273$; Degrees of freedom $(20-15)=5 ; p<0.001 ; \mathrm{NFI}=0.939$; RFI $=0.917$; IFI $=$ 0.947; TLI $=0.937$, CFI $=0.946$; RMSEA $=0.065$; HOELTER $=2,453(p<0.05)$ and, $617(p<0.01)]$. The total scale showed good internal consistency (Alpha $=0.956$; Part $1=$ 0.932 , Part $2=0.832$; Spearman-Brown $=0.962$; Guttman $=0.932$ ).

\section{Resilience}

Measured using the CD-RISC Scale (100) in its validated Spanish version $(101,102)$. This scale assesses different aspects of how one faces difficulties and is able to overcome them. The results offer information on perception of competence, acceptance of change and secure relationships, tolerance/stress management, control and spirituality (103). Adequate reliability and validity values were obtained in Spanish samples, and a five-factor structure: F1. Persistence/tenacity, strong self-efficacy (COMPETENCE); F2: Emotional and cognitive control under pressure (STRESS); F3: Adaptability/ability to bounce back and secure relationships (CHANGE); F4: Perceived Control (CONTROL), and F5: Spirituality (SPIRITUALITY).

\section{Factors of Stress}

Cuestionario de Estrés Académico, CEA [Academic stress questionnaire] $(35,104)$. The scale's internal structure was analyzed. In order to do so, we conducted a confirmatory factor analysis (CFA) of the whole set of data from our sample, thus verifying the second-level structure. The default model has good fit [Chi-Square $=66,457, \mathrm{df}=13, p<0.001$; CFI $=0.935$, TLI $=0.961$, IFI $=0.947$, RFI $=0.965$ and NFI $=0.947$; RMSEA $=0.057$; HOELTER $=0.430(p<0.05)$ and $0.532(p<0.01)]$. The proposed model contains 53 items with a seven-factor structure having two dimensions, where one factor differs from the original version. The resulting dimensions and factors were: (1) Dimension of Stress in Learning: Task Overload (Factor 2), Dificulties of Performance Control (F3), Social climate (Factor 5), and Test Anxiety (Factor 7); (2) Dimension of Stress in Teaching: Methodology difficulties (Factor 1), Public speaking (Factor 4); Content lacks value (Factor 6 ). Overall reliability $=0.961$; part $1=0.932$, part 2 $=0.946$.

\section{Effects of Stress}

Stress Response Questionnaire, CRE (105). The scale's psychometric properties were found to be adequate in this sample of Spanish students. The confirmatory structural model of the CRE has the following dimensions (Chi-square $=846,503$; Degrees of freedom $(275-76)=199, p<0.001$; NFI $=0.952$; RFI $=0.965 ;$ IFI $=0.953)$ : F1. Burnout; F2. Sleep Difficulties; F3. Irritability; F4. Negative thoughts; F5. Agitation. Scale unidimensionality and metric invariance were confirmed in the assessment samples [RMSEA $=0.046$; CFI 0.922 and TLI 0.901; HOELTER $=431(p<0.05)$ and $459(p<0.01)]$. Cronbach alpha was 0.920 , part $1=0.874$ and part $2=0.863$.

\section{Procedure}

Research participants received information about this research study and gave their informed consent online, through the Academic Stress e-Coping platform (106), in the context of a more extensive research project (R\&D Project ref. 2019-2021). For more detail, see http://www.inetas.net.

The questionnaires were completed by students on a voluntary basis. Data were collected and processed with the students' informed consent, in accordance with the Ethical and Deontological Principles of Psychology. The data were handled anonymously, in a group format, and were stored in a protected database at the University. The Bioethics Committee approved the Project and the instruments used (ref. 2018.170). 


\section{Data Analysis}

Using an ex post facto, transversal design (107), we performed three types of analyses. The usual assumptions of regression analysis were tested beforehand.

\section{Preliminary Analysis}

First, we explored the quality of the data by testing for outliers and missing cases. We tested for univariate outliers by calculating the typical scores of each variable, considering cases with $\mathrm{Z}$ scores outside the \pm 3 range to be potentially atypical cases $(108,109)$. On the other hand, the Mahalanobis distance (D2) was used to detect atypical combinations of variables (atypical multivariate cases), a statistical measure of an individual's multidimensional distance from the centroid or mean of the given observations (107). This procedure detects significant distances from the typical combinations or centroids of a set of variables. The literature suggests removing univariate and multivariate outliers, or reassigning them the nearest extreme score (110). The procedure was carried out using SPSS (v.26, IBM, Armonk, NY, USA), which provides a specific routine for missing values analysis that determines the magnitude of missing values and whether they are presented in a systematic or random manner.

Assumptions related to sample size, independence of errors, univariate and multivariate normality, linearity, multicollinearity, recursion, and interval measurement level were also evaluated, and represented acceptable reliability levels. Regarding the sample size, inclusion of 10-20 cases per parameter is recommended, and at least 200 observations (111).

Independence of errors means that the error term of each endogenous variable must not be correlated with other variables. In order to test for univariate normality, we examined the distribution of each observed variable, and its indices of asymmetry and kurtosis. Asymmetry values $>3$ and kurtosis $>10$ suggest that the data should be transformed. On the other hand, values $<70$ on the Mardia multivariate index indicate that distance from the multivariate normality is not a critical deterrent to this analysis. Although one of the assumptions is level of interval measurement, in some cases, variables measured at a nominal or ordinal level were used, as long as the distribution of scores, particularly of the dependent variables, was not markedly asymmetric.

As a preliminary analysis, we checked for normal sample distribution using the Kolmogorov-Smirnoff test for dependent variables. We also used the Hoelter Index to test for adequate sample size (75). In addition, we conducted analyses of linearity and atypical values, missing and influential cases, as well as critical values of multivariate normality; recommended values for the multivariate index of kurtosis, or Mardia coefficient, were $<0.70$ (112).

\section{Predictive Analysis}

We applied multiple regression analysis, using SPSS (v.25), for Hypotheses 1-3.

\section{Structural Prediction and Mediational Models}

Hypotheses 4 and 5 were tested using a Structural Equation Model (SEM) and mediational model, for complex measurement (113). We assessed model fit by first examining the ratio of chi-square to degrees of freedom, then the Comparative Fit Index (CFI), Normed Fit Index (NFI), Incremental Fit Index (IFI), and Relative Fit Index (RFI). All fit measures of the incremental model were above the suggested limit of 0.90 (114): Comparative Fit Index (CFI), Incremental Fit Index (IFI), Normed Fit Index (NFI), Relative Fit Index (RFI) and Tucker-Lewis Index (TLI). The value of the Comparative fit index (CFI) was equal to 0.928, which is also satisfactory. We replicated the results of the original scale. The value of the Root Mean Square Error of Approximation (RMSEA) was 0.084 , less than the warning value of 0.09 (115). These should ideally be $>0.90$. We also used the Hoelter Index to determine adequacy of sample size. AMOS (v.22) was used for these analyses. Keith (116) proposed the following beta coefficients as research benchmarks for direct effects: $<0.05$ is considered too small to be meaningful, above 0.05 is small but meaningful, above 0.10 is moderate, and above 0.25 is large. For indirect effects, we used Kenny's definition (117) of an indirect effect as the product of two effects; using Keith's benchmarks above, we propose a small indirect effect $=0.003$, moderate $=0.01$, and large $=0.06$, values that are significant in the sphere of education.

\section{RESULTS}

\section{Preliminary Analyses: Normality Assumptions}

Results from the analyses used to test normality, a prerequisite for linear analysis, showed adequate distribution of sample variability. See Table 1.

\section{Specific Linear Prediction Relationships Between the Big Five Factors and Resilience (Hypothesis 1)}

Regression analyses showed that the personality factors had differential predictive value for Resilience factors. The regulatory personality factors ( $\mathrm{C}$ and $\mathrm{E}$ ) significantly and positively predicted total resilience, as well as proactive resilience factors (competence, change and control), but this was not so for reactive factors (stress management and spirituality). $\mathrm{C}$ and E most strongly predicted Perceived competence, followed by Perceived control. The non-regulatory personality factors ( $O$ and A) did not generally predict total resilience, although they were significant predictors of certain reactive resilience factors, positively predicting stress management and negatively predicting spirituality. The dysregulatory personality factor (N) negatively predicted total resilience and most of its factors, except for spirituality, where it had no predictive power. See Table 2. 
TABLE 1 | Descriptive values of the study variables $(n=405)$.

\begin{tabular}{|c|c|c|c|c|c|c|c|c|c|}
\hline Variable & Min & Max & $M(s d)$ & Mean std. error & Asymmetry & $\begin{array}{c}\text { Standard } \\
\text { asymmetry error }\end{array}$ & Kurtosis & $\begin{array}{c}\text { Standard } \\
\text { kurtosis error }\end{array}$ & Kolmogoroff-Sminoff \\
\hline C & 1.92 & 5.00 & $3.733(0.566)$ & 0.025 & -0.138 & 0.109 & -0.288 & 0.217 & $0.037 . p>0.200$ \\
\hline$E$ & 1.23 & 4.92 & $3.592(0.560)$ & 0.025 & -0.517 & 0.109 & 0.557 & 0.217 & $0.048 . p>0.112$ \\
\hline $\mathrm{O}$ & 1.92 & 4.85 & $3.496(0.474)$ & 0.021 & 0.018 & 0.110 & -0.003 & 0.220 & $0.041 . p>0.132$ \\
\hline$A$ & 2.46 & 5.00 & $4.024(0.474)$ & 0.021 & -0.280 & 0.109 & -0.316 & 0.218 & $0.026 . p>0.215$ \\
\hline $\mathrm{N}$ & 1.08 & 5.00 & $2.616(0.635)$ & 0.028 & 0.255 & 0.109 & 0.120 & 0.217 & $0.050 . p>0.120$ \\
\hline Resilience & 1.82 & 4.86 & $3.760(0.016)$ & 0.016 & -0.573 & 0.089 & 0.576 & 0.178 & $0.054 . p>0.100$ \\
\hline Stress factors & 1.29 & 4.52 & 2.993 (0.032) & 0.045 & -0.166 & 0.059 & -0.175 & 0.122 & $0.042 . p>0.200$ \\
\hline Stress symptoms & 1.04 & 5.00 & $2.308(0.056)$ & 0.031 & 0.487 & 0.107 & 0.425 & 0.215 & $0.045 . p>0.150$ \\
\hline
\end{tabular}

C, Conscientiousness; E, Extraversion; O, Openness to Experience; A, Agreeability; N, Neuroticism.

TABLE 2 | Multiple regression between the BF factors and Resilience $(n=405)$.

\begin{tabular}{|c|c|c|c|c|c|c|}
\hline Big five & Competence & Stress mgmt & Change & Control & Spirituality & Total \\
\hline C & $0.310^{\star \star}$ & 0.001 & $0.165^{\star}$ & $0.321^{\star *}$ & 0.097 & $0.261^{\star *}$ \\
\hline$E$ & $0.297^{\star \star}$ & $0.214^{\star \star}$ & $0.265^{\star \star}$ & $0.242^{\star *}$ & 0.098 & $0.276^{\star *}$ \\
\hline $\mathrm{O}$ & 0.063 & $0.260^{\star \star}$ & $0.144^{\star}$ & -0.032 & $-0.123^{\star}$ & 0.051 \\
\hline$A$ & -0.087 & -0.082 & -0.04 & 0.002 & $0.122^{\star}$ & 0.045 \\
\hline $\mathrm{N}$ & $-0.298^{\star \star}$ & $-0.254^{\star \star}$ & $-0.268^{\star \star}$ & $-0.222^{\star *}$ & -0.061 & $-0.210^{\star \star}$ \\
\hline$F_{(5,415)}$ & $46.991^{\star \star}$ & $22.402^{\star \star}$ & $33.487^{\star \star}$ & $33.496^{\star \star}$ & $4.559^{\star \star}$ & $23.529^{\star \star}$ \\
\hline Adj. $R^{2}$ & 0.376 & 0.239 & 0.279 & 0.314 & 0.052 & 0.319 \\
\hline
\end{tabular}

C, Conscientiousness; E, Extraversion; O, Openness to Experience; A, Agreeability; N, Neuroticism. ${ }^{*} p<0.05,{ }^{* *} p<0.01,{ }^{* * *} p<0.001$.

TABLE 3 | Multiple regression between the BF factors, and factors of academic stress $(n=405)$.

\begin{tabular}{|c|c|c|c|c|c|c|c|c|c|}
\hline Big five & $\begin{array}{l}\text { Method } \\
\text { diff. }\end{array}$ & $\begin{array}{l}\text { Public } \\
\text { spkg. }\end{array}$ & $\begin{array}{l}\text { Content } \\
\text { value }\end{array}$ & Overload & $\begin{array}{l}\text { Soc. } \\
\text { climate }\end{array}$ & $\begin{array}{c}\text { Low Achievemt } \\
\text { control }\end{array}$ & $\begin{array}{l}\text { Teaching } \\
\text { factors }\end{array}$ & $\begin{array}{l}\text { Learng. } \\
\text { factors }\end{array}$ & $\begin{array}{l}\text { Acad. stress } \\
\text { factors }\end{array}$ \\
\hline C & -0.054 & 0.007 & -0.034 & $-0.201^{\star \star}$ & -0.023 & $-0.167^{\star \star}$ & -0.026 & $-0.156^{\star \star}$ & $-0.118^{\star}$ \\
\hline$E$ & $-0.150^{\star \star}$ & $-0.245^{\star \star \star}$ & 0.012 & $-0.200^{\star \star}$ & -0.035 & $-0.142^{*}$ & $-0.165^{\star \star}$ & $-0.174^{\star \star}$ & $-0.202^{\star *}$ \\
\hline $\mathrm{O}$ & 0.003 & $-0.242^{\star \star \star}$ & -0.002 & -0.052 & 0.101 & -0.038 & $-0.135^{\star}$ & -0.024 & -0.051 \\
\hline$A$ & $0.195^{\star \star \star}$ & $0.129^{\star \star \star}$ & 0.030 & 0.052 & -0.026 & $0.167^{\star \star}$ & $0.124^{\star}$ & $0.126^{\star}$ & $0.152^{\star *}$ \\
\hline $\mathrm{N}$ & $0.333^{\star \star \star}$ & $0.302^{\star \star \star}$ & $0.212^{\star \star \star}$ & $0.139^{\star \star \star}$ & $0.215^{\star \star \star}$ & $0.437^{\star \star \star}$ & $0.380^{\star \star \star}$ & $0.361^{\star \star \star}$ & $0.403^{\star \star \star}$ \\
\hline$F_{(5,367)}$ & $10.751^{\star *}$ & $23.087^{\star \star \star}$ & $4.318^{\star \star}$ & $20.858^{\star \star}$ & $4.273^{\star \star}$ & $24.230^{* *}$ & $17.060^{\star \star \star}$ & $15.571^{\star \star}$ & $18.557^{\star \star \star}$ \\
\hline$R^{2}$ & 0.180 & 0.216 & 0.052 & 0.219 & 0.053 & 0.248 & 0.196 & 0.178 & 0.228 \\
\hline
\end{tabular}

C, Conscientiousness; E, Extraversion; O, Openness to Experience; A, Agreeability; N, Neuroticism. ${ }^{*} p<0.05,{ }^{* *} p<0.01,{ }^{* * \star} p<0.001$. Bold values indicate major effects.

\section{Linear Predictive Relationships of the Big Five, for Factors and Symptoms of Academic Stress (Hypothesis 1)}

Results from the regression analysis offered interesting clarifications. The regulatory personality factors (C and E) were significant, negative predictors of total factors of academic stress, especially factors pertaining to the learning process (overload, achievement control). Non-regulatory personality factors $(\mathrm{O}, \mathrm{A})$ were mixed predictors of stress factors $(\mathrm{O}$ negatively and A positively). Worthy of note is that factor A was a significant, positive predictor of stress factors from the teaching. The dysregulatory personality factor showed the greatest predictive power $(B=0.403 ; p<0.001)$, as a significant, positive predictor of total stress factors, most noticeably of lack of control over achievement $(B=0.437 ; p<0.001)$.

The same tendency was repeated in the prediction of stress symptoms. The regulatory personality factors (C and $\mathrm{E})$ were significant, negative predictors of total symptoms of academic stress, especially of burnout and negative thinking. The nonregulatory personality factors $(\mathrm{O}, \mathrm{A})$ did not show significant predictive power on total stress factors but were differential predictors of certain specific factors. The dysregulatory personality factor was a significant, positive predictor of total stress symptoms, with the greatest power $(B=0.564 ; p<0.001)$, where irritability was most noteworthy $(B=0.638 ; p<0.001)$. See Tables 3, 4. 
TABLE 4 | Multiple regression between the BF factors, and symptoms of academic stress $(n=405)$.

\begin{tabular}{|c|c|c|c|c|c|c|}
\hline Big five & Burnout & Sleep diff. & Irritability & Neg. thoughts & Restlessness & $\begin{array}{c}\text { Academic } \\
\text { stress symp. }\end{array}$ \\
\hline C & $-0.223^{\star \star}$ & $-0.010^{\star}$ & -0.019 & $-0.125^{\star \star}$ & -0.044 & $-0.111^{*}$ \\
\hline$E$ & $-0.165^{\star}$ & $-0.129^{*}$ & $-0.162^{\star \star \star}$ & $-0.309^{\star \star \star}$ & -0.077 & $-0.204^{\star \star}$ \\
\hline $\mathrm{O}$ & -0.031 & $0.106^{\star}$ & 0.015 & -0.083 & -0.022 & -0.014 \\
\hline A & $0.158^{\star \star}$ & -0.030 & $-0.114^{\star \star}$ & $0.169^{\star \star}$ & 0.055 & 0.074 \\
\hline $\mathrm{N}$ & $0.432^{\star \star \star}$ & $0.408^{\star \star \star}$ & $0.638^{\star \star \star}$ & $0.456^{\star \star \star}$ & $0.391^{\star \star \star}$ & $0.564^{\star \star \star}$ \\
\hline$F_{(5,400)}$ & $32.338^{\star \star}$ & $18.787^{\star \star}$ & $72.615^{\star \star \star}$ & $42.482^{\star \star}$ & $15.617^{\star \star}$ & $47.648^{\star \star \star}$ \\
\hline$R^{2}$ & 0.278 & 0.176 & 0.460 & 0.347 & 0.153 & 0.389 \\
\hline
\end{tabular}

C, Conscientiousness; E, Extraversion; O, Openness to Experience; A, Agreeability; N, Neuroticism. ${ }^{*} p<0.05,{ }^{* *} p<0.01,{ }^{* \star *} p<0.001$. Bold values indicate major effects.

TABLE 5 | Multiple regression between the factors of resilience and factors of academic stress $(n=405)$.

\begin{tabular}{|c|c|c|c|c|c|c|c|c|c|}
\hline Resilience & Method diff. & Public spkg. & Content value & Overload & Soc. climate & $\begin{array}{c}\text { Achievemt } \\
\text { control }\end{array}$ & Teaching factors & Lrng. factors & $\begin{array}{l}\text { Acad. stress } \\
\text { factors }\end{array}$ \\
\hline Competence & 0.054 & -0.085 & -0.027 & -0.096 & 0.001 & $-0.158^{\star \star}$ & -0.022 & -0.070 & -0.027 \\
\hline Change & $-0.138^{\star}$ & $-0.176^{\star \star}$ & -0.095 & $-0.169^{\star \star}$ & -0.045 & -0.058 & $-0.172^{*}$ & $-0.232^{\star \star}$ & $-0.232^{\star \star}$ \\
\hline Control & -0.067 & -0.059 & -0.092 & $-0.091^{*}$ & -0.102 & $-0.139^{\star \star}$ & $-0.112^{*}$ & -0.110 & $-0.138^{*}$ \\
\hline Stress & -0.114 & $-0.136^{\star}$ & 0.024 & -0.056 & 0.004 & -0.058 & -0.076 & -0.040 & -0.022 \\
\hline Spirituality & 0.033 & $0.099^{\star}$ & -0.019 & $0.079^{\star}$ & $0.093^{\star}$ & $0.129^{\star \star}$ & 0.063 & 0.085 & 0.071 \\
\hline$F_{(5,392)}$ & $2.385^{\star \star}$ & $16.793^{\star *}$ & 3.383 & $16.585^{\star \star}$ & $3.642^{\star}$ & $15.944^{\star \star}$ & $10.234^{\star \star}$ & $10.753^{\star \star}$ & $11.990 * *$ \\
\hline$R^{2}$ & 0.025 & 0.143 & 0.033 & 0.120 & 0.028 & 0.086 & 0.101 & 0.113 & 0.113 \\
\hline
\end{tabular}

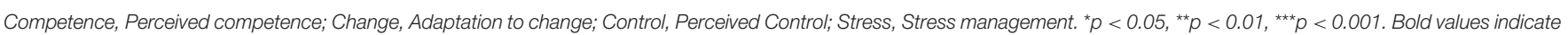
major effects.

TABLE 6 | Multiple regression between factor of stress, and symptoms of academic stress $(n=405)$.

\begin{tabular}{|c|c|c|c|c|c|c|}
\hline Resilience & Burnout & Sleep diff. & Irritability & Neg. thoughts & Restlessness & Stress symptoms \\
\hline Competence & $-0.195^{\star \star}$ & -0.069 & $-0.168^{\star \star}$ & $-0.313^{\star \star}$ & -0.091 & $-0.187^{\star}$ \\
\hline Change & -0.069 & -0.107 & -0.069 & $-0.156^{\star}$ & -0.080 & $-0.126^{\star}$ \\
\hline Control & $-0.139^{\star \star}$ & $-0.114^{\star \star}$ & $-0.126^{\star \star}$ & -0.051 & $-0.093^{\star}$ & $-0.122^{*}$ \\
\hline Stress & 0.021 & 0.027 & -0.042 & -0.028 & -0.004 & -0.023 \\
\hline Spirituality & $0.081^{*}$ & -0.019 & -0.020 & 0.056 & -0.017 & -0.054 \\
\hline$F_{(5,382)}$ & $16.317^{\star \star}$ & $8.093^{\star \star}$ & $17.322^{\star *}$ & $40.067^{\star \star}$ & $7.500^{\star \star}$ & $21.557^{\star *}$ \\
\hline$R^{2}$ & 0.110 & 0.051 & 0.111 & 0.228 & 0.054 & 0.152 \\
\hline
\end{tabular}

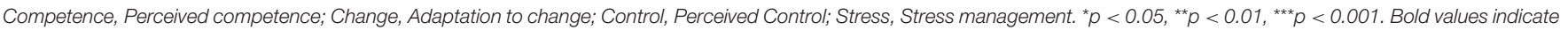
major effects.

\section{Linear Predictive Relationships of Resilience Components for Factors/Symptoms of Academic Stress (Hypothesis 2)}

Regression analyses showed differential predictive values. The proactive factors of resilience (adaptation to change, perceived control) were significant, negative predictors of the level of total stress. Specifically, the proactive factors (competence, change, control) had the greatest negative predictive power for academic stress factors, especially regarding work overload and achievement control. However, the reactive factors had less predictive power, and in the case of spirituality, there was even positive prediction of stress factors (public speaking, overload, achievement control), thereby confirming its reactive, stressenduring value.
In complementary manner, this tendency was repeated for stress symptoms. The proactive factors mentioned (competence, change and perceived control) were significant, negative predictors of stress symptoms, while the reactive factors (stress management, spirituality) were not so. Worth mentioning was spirituality as a negative predictor of burnout, indicating the buffering role of this factor. See Tables 5, 6 .

\section{Linear Predictive Relationships of Factors and Symptoms of Academic Stress (Hypothesis 3)}

The directionality of the regression results consistently showed that stress factors from the learning process had the greatest predictive power on stress symptoms. The factor of loss of 
TABLE 7 | Multiple regression between factor of stress, and symptoms of academic stress $(n=405)$.

\begin{tabular}{|c|c|c|c|c|c|c|}
\hline $\begin{array}{l}\text { Stress } \\
\text { factors of teaching }\end{array}$ & Burnout & Sleep diff. & Irritability & Neg. thoughts & Restlessness & Stress symptoms \\
\hline Method diff. & 0.077 & 0.068 & 0.038 & -0.063 & -0.013 & 0.033 \\
\hline Public spkg. & $0.108^{\star \star}$ & 0.001 & 0.058 & $0.129^{\star}$ & 0.025 & 0.070 \\
\hline Content value & 0.064 & -0.98 & 0.036 & -0.076 & -0.078 & -0.034 \\
\hline Overload & 0.282 & 0.075 & $0.123^{\star}$ & $0.130^{\star}$ & 0.048 & $0.156^{\star \star}$ \\
\hline Social climate & -0.008 & 0.098 & $0.126^{\star \star}$ & 0.020 & $0.181^{\star}$ & $0.115^{\star \star}$ \\
\hline $\begin{array}{l}\text { Loss of achievement } \\
\text { control }\end{array}$ & $0.184^{\star \star}$ & $0.305^{\star \star}$ & $0.249^{\star *}$ & $0.466^{\star *}$ & $0.344^{\star \star}$ & $0.339^{\star \star}$ \\
\hline$F_{(5,382)}$ & $40.217^{\star \star}$ & $17.923^{\star *}$ & $26.767^{\star \star}$ & $40.536^{\star *}$ & $22.983^{\star \star}$ & $50.775^{\star \star}$ \\
\hline$R^{2}$ & 0.322 & 0.183 & 0.241 & 0.326 & $(0.215)$ & 0.401 \\
\hline
\end{tabular}

${ }^{\star} p<0.05,{ }^{\star \star} p<0.01,{ }^{\star \star \star} p<0.001$. Bold values indicate major effects.

TABLE 8 | Models of structural linear results of the variables.

\begin{tabular}{|c|c|c|c|c|c|c|c|c|c|c|}
\hline \multirow[t]{2}{*}{ Model } & \multirow[t]{2}{*}{ Degrees of freedom } & \multirow[t]{2}{*}{ Chi-square } & \multirow[t]{2}{*}{$p<$} & \multirow[t]{2}{*}{ NFI } & \multirow[t]{2}{*}{ RFI } & \multirow[t]{2}{*}{ IFI } & \multirow[t]{2}{*}{ TLI } & \multirow[t]{2}{*}{ CFI } & \multirow[t]{2}{*}{ RMSEA } & \multirow{2}{*}{$\frac{\text { Hoelter }}{0.005-0.001}$} \\
\hline & & & & & & & & & & \\
\hline 1. $\mathrm{BF}$ & $(152-51): 101$ & 883.554 & 0.001 & 0.804 & 0.832 & 0.820 & 0.853 & 0.819 & 0.075 & 215-235 \\
\hline 2. $B F$ and $R$ & (252-67): 185 & 1233.657 & 0.001 & 0.905 & 0.956 & 0.929 & 0.959 & 0.928 & 0.053 & 293-359 \\
\hline
\end{tabular}

Model 1: Big Five; Model 2: Big Five and Resilience.

TABLE 9 | Total, indirect, and direct effects of the variables in this study, and 95\% bootstrap confidence intervals (Cl).

\begin{tabular}{|c|c|c|c|c|c|c|c|c|c|}
\hline Predictive variable & Criterion variable & Total effect & $\mathrm{Cl}(95 \%)$ & Direct effect & $\mathrm{Cl}(95 \%)$ & Indirect effect & $\mathrm{Cl}(95 \%)$ & $\begin{array}{l}\text { Results, } \\
\text { effects }\end{array}$ & Cl (95\%) \\
\hline $\mathrm{BF} \rightarrow$ & Resilience & 0.74 & $(0.69,0.77)$ & 0.74 & $(0.69,0.77)$ & 0.00 & $(-0.03,0.02)$ & Direct only & $(0.69,0.74)$ \\
\hline $\mathrm{BF} \rightarrow$ & Stress factors & -0.34 & $(-0.11,-0.17)$ & -0.09 & $(-30,38)$ & -0.24 & $(-0.22,-0.27)$ & $\begin{array}{l}\text { Partial } \\
\text { mediation }\end{array}$ & $(-0.22,-0.27)$ \\
\hline $\mathrm{BF} \rightarrow$ & Stress symptoms & -0.24 & $(-0.20,-0.28)$ & 0.00 & $(-0.20,-0.28)$ & -0.24 & $(-0.20,-0.27)$ & Full mediation & $(-0.20,-0.27)$ \\
\hline Resilience $\rightarrow$ & Stress factors & -0.34 & $(-31,-0.37)$ & -0.34 & $(-31,-0.37)$ & 0.00 & $(-0.02,0.02)$ & Direct only & $(-31,-0.37)$ \\
\hline Resilience $\rightarrow$ & Stress symptoms & -0.24 & $(-0.20,-0.28)$ & 0.00 & $(-0.03,0.04)$ & -0.24 & $(-0.20,-0.28)$ & $\begin{array}{l}\text { Full mediation } \\
\text { (suppression) }\end{array}$ & $(-0.20,-0.28)$ \\
\hline Stress factors $\rightarrow$ & Stress symptoms & 0.70 & $(0.68,72)$ & 0.70 & $(0.68,72)$ & 0.00 & $(-0.03,0.02)$ & Direct only & $(0.68,72)$ \\
\hline
\end{tabular}

Cl, confidence interval. Bootstrapping sample size $=430$.

achievement control was especially relevant, predicting all stress symptoms. See Table 7.

\section{Structural Prediction Model (Hypothesis 4)}

Two structural models were tested. The first model took only the $\mathrm{BF}$ factors as independent variables. The second modelwhich attained greater statistical significance-took both BF and Resilience as criterion variable. All these measures were indicative of good model fit. See Table 8.

Model 2 reflected how BF factors (except for $\mathrm{N}$ ) were positive predictors of Resilience (R), and how Stress Factors (SF) positively predicted Stress Symptoms (SS). Regarding the indirect effects of the BF Factors, these factors proved to have: (1) a positive effect on factors of Resilience; and (2) a negative effect on Stress Factors (SF) and Stress Symptoms (SS), as well as their components.
In addition, resilience factors showed a negative effect on the factors and symptoms of stress. See Table 9 and Figure 1.

Figure 1 shows general prediction relationships of the model. The Big Five personality factors, except for Neuroticism (N) ( $B=-0.27)$, are positive predictors of resilience (RES). The proactive components of resilience (competence, change and control), as well as its reactive components (stress management and spirituality), are negative predictors of stress factors (STRESSFACT), although spirituality shows less weight in this prediction (SPIRIT) $(B=0.17)$. The general mediating effect of resilience is thereby demonstrated. Stress factors may originate in aspects of the teaching process as well as the learning process; they are positive predictors of academic stress symptoms (STRESSSYMT). However, this general mediation model has a basic limitation, in that it cannot confirm the 


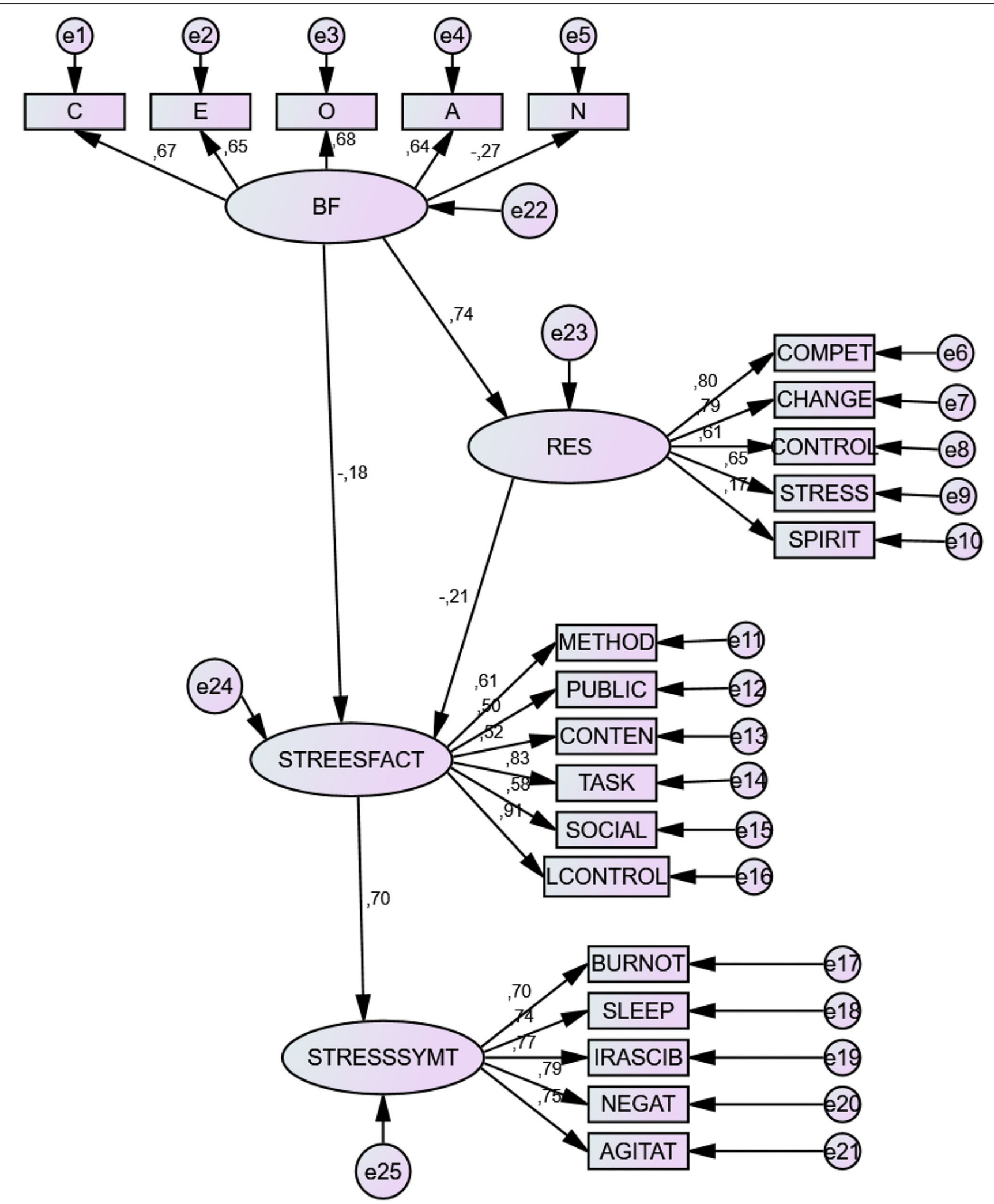

FIGURE 1 | Structural Prediction of variables in the second model. E, Extraversion; C, Conscientiousness; N, Neuroticism; O, Openness to Experience; A, Agreeability; RESIL, Resilience; STRESSFACT, Stress Factors; STRESSSYMNT, Stress symptoms. 
TABLE 10 | Mediational models for BF factors, resilience, and stress factors and symptoms.

\begin{tabular}{|c|c|c|c|c|c|c|c|c|c|c|}
\hline $\begin{array}{l}\text { Model/ } \\
\text { factor }\end{array}$ & $X 2, \mathrm{df} ; p>$ & $\mathrm{X} 2 / \mathrm{df}$ & $\begin{array}{c}\text { NFI } \\
\text { Delta1 }\end{array}$ & $\begin{array}{l}\text { RFI } \\
\text { rho1 }\end{array}$ & $\begin{array}{c}\text { IFI } \\
\text { Delta2 }\end{array}$ & TLI & CFI & RMSEA & $\begin{array}{l}\text { Hoelter } \\
p<0.05\end{array}$ & $\begin{array}{l}\text { Hoelter } \\
p<0.01\end{array}$ \\
\hline 1. C & $\begin{array}{c}1.567 ;(14-13) 1 \\
p<0.133\end{array}$ & 1.576 & 0.995 & 0.953 & 0.998 & 0.983 & 0.998 & 0.01 & 3,834 & 6,622 \\
\hline 2. $E$ & $\begin{array}{l}2.061 ; 1 \\
p<0.151\end{array}$ & 2.061 & 0.994 & 0.936 & 0.997 & 0.966 & 0.997 & 0.02 & 2,916 & 5,036 \\
\hline 3. 0 & $\begin{array}{l}4.873 ; 1 \\
p<0.02\end{array}$ & 4.873 & 0.983 & 0.829 & 0.986 & 0.859 & 0.986 & 0.05 & 1,233 & 2,130 \\
\hline 4. $A$ & $\begin{array}{c}2.678 ; 1 \\
p<0.102\end{array}$ & 2.678 & 0.991 & 0.908 & 0.994 & 0.940 & 0.994 & 0.03 & 2,244 & 3,875 \\
\hline 5. $\mathrm{N}$ & $\begin{array}{c}0.712 ; 1 \\
p<0.339\end{array}$ & 0.712 & 0.998 & 0.985 & 1.00 & 1.00 & 1.00 & 0.001 & 8,443 & 14,582 \\
\hline
\end{tabular}

C, Conscientiousness; E, Extraversion; O, Openness to Experience; A, Agreeability; N, Neuroticism.

direct and indirect effect of each personality factor. On this account, other specific prediction models were carried out for each personality factor and resilience as a mediating variable.

\section{Mediational Model (Hypothesis 5)}

The results from testing the five mediation models were differentially significant. Model 1 (Conscientiousness) and Model 5 (Neuroticism) showed the best fit and consistency, especially the latter. Model 2 (Extraversion), Model 3 (Openness to Experience) and Model 4 (Agreeability), appeared in the direction expected, though with lower significance. See Table 10.

The specific analysis of each model shows the directionality of the predictions. Model 1 (Conscientiousness) shows resilience as a significant, positive mediating factor, between personality component $\mathrm{C}$ and academic stressors. Model 2 (Extraversion) also shows resilience as a positive mediating factor with regard to academic stressors. In Model 3 (Openness to experience) and Model 4 (Agreeability), resilience contributes an important mediating element to both of these factors that were less predictive of stress factors and symptoms. Model 5 shows a more consistent positive mediating role of resilience in buffering the stress-predicting effects of Neuroticism. See Table 11.

Observe in Models 1 and 2 (C, E) that the direct and indirect effects of resilience are greater and positive in nature. In Models 3 and $4(\mathrm{O}, \mathrm{A})$, effects are positive but smaller. In Model 5 $(\mathrm{N})$, resilience shows robust, negative direct and indirect effects, converting it into a buffering variable (a canceling mediational effect) on stress factors and symptoms.

\section{DISCUSSION AND CONCLUSION}

The proposed hypotheses can reasonably be accepted, based on the results obtained here.

The first hypothesis, that the different types of regulatory factors of the BF model would differentially predict the proactive and reactive factors of resilience, was fulfilled overall. These results support prior evidence, which showed that BF personality factors have clear connections to the construct of resilience $(77,78,118)$; furthermore, that resilience is positively associated with a well-adjusted personality profile $(85,119)$. Researchers have shown interest in identifying the individual personality traits or cluster of traits that are positively associated with resilience. These personality traits may be the "antecedents of resilience" and not really components of resilience itself (120). The components of resilience are very necessary in modern life, to navigate through work, study, and relationships in times of uncertainty and lack of predictability (121). Our investigation represents an advance in knowledge, contributing evidence that identifies which components of the BF model have predicted total resilience. The regulatory behavioral components of the $\mathrm{BF}$ model (C, E) have predicted proactive factors of resilience (perceived competence, adaptation to change, and perceived control); the non-regulatory $\mathrm{BF}$ factors $(\mathrm{O}, \mathrm{A})$ were not predictive of the proactive factors of resilience but showed more prediction toward the reactive factors (stress management and spirituality); finally, the BF dysregulatory factor appeared as a significant negative predictor of total resilience and of reactive resilience factors. This is a central contribution toward understanding the relations between the two constructs, and goes in the direction of similar effects that have recently been reported $(85,122,123)$. Moreover, indirect support is also found for the regulatory continuum model proposed by $S R L v$ s. ERL Theory (65). In short, a well-adjusted personality profile positively predicts resilience.

Regarding the second part of this hypothesis, the same predictive scheme was verified with regard to the factors and symptoms of academic stress. While factors $\mathrm{C}$ and A negatively predicted the factors and symptoms of academic stress, factors $\mathrm{O}$ and $\mathrm{A}$ had a neutral relation to them, and factor $\mathrm{N}$ was a negative predictor. The regulatory $\mathrm{BF}$ components (C, E) proved to be protective factors against stress (its factors and symptoms), while the non-regulatory factors $(\mathrm{O}, \mathrm{A})$ were unrelated to stress factors and symptoms, and the dysregulatory factor $(\mathrm{N})$ appeared as a risk factor for stress (factors and symptoms). These results concur with prior evidence $(124,125)$. Different studies have found that the $\mathrm{C}$ and $\mathrm{E}$ personality traits are predictors of academic resilience. Students that exhibit $\mathrm{C}$ are well-prepared, they self-regulate, and can maintain calm in the face of stress $(119,126)$. E and $\mathrm{C}$ students have more resources under adverse conditions. The strong association 
TABLE 11 | Total, indirect, and direct effects of the variables in this study, and 95\% bootstrap confidence intervals (CI).

\begin{tabular}{|c|c|c|c|c|c|c|c|c|c|}
\hline Predictive variable & Criterion variable & Total effect & $\mathrm{Cl}(95 \%)$ & Direct effect & $\mathrm{Cl}(95 \%)$ & Indirect effect & $\mathrm{Cl}(95 \%)$ & Results, effects & Cl (95\%) \\
\hline \multicolumn{10}{|l|}{ Model 1 (C) } \\
\hline Conscientiousness $\rightarrow$ & Resilience & 0.46 & $(0.43,0.49)$ & 0.46 & $(0.43,0.49)$ & 0.00 & $(-0.02,0.02)$ & Direct only & $(0.43,0.49)$ \\
\hline Conscientiousness $\rightarrow$ & Academic Stress Factors & -0.24 & $(-0.28,-0.20)$ & -0.16 & $(-0.20,-0.13)$ & -0.07 & $(-0.10,-0.04)$ & Partial mediation & $(-0.10,-0.04)$ \\
\hline Conscientiousness $\rightarrow$ & Academic Stress Symptoms & -0.16 & $(-0.19,-0.14)$ & -0.03 & $(-0.05,-0.01)$ & -0.14 & $(-0.10,-0.19)$ & Full mediation & $(-0.10,-0.19)$ \\
\hline Resilience & Academic Stress Factors & -0.19 & $(-0.16,-0.22)$ & -0.19 & $(-0.15,-0.21)$ & 0.00 & $(-0.03,0.03)$ & Direct only & $(-0.15,-0.21)$ \\
\hline Resilience & Academic Stress Symptoms & -0.11 & $(-0.09,-0.12)$ & 0.00 & $(-0.04,0.03)$ & -0.11 & $(-0.08,-0.14)$ & $\begin{array}{l}\text { Full mediation } \\
\text { (supression) }\end{array}$ & $(-0.08,-0.14)$ \\
\hline \multicolumn{10}{|l|}{ Model 2 (E) } \\
\hline Extravers $\rightarrow$ & Resilience & 0.45 & $(0.49,0.53)$ & 0.45 & $(0.49,0.53)$ & 0.00 & $(-0.04,0.03)$ & Direct only & $(0.49,0.53)$ \\
\hline Extravers $\rightarrow$ & Academic Stress Factors & -0.18 & $(-0.23,-0.14)$ & -0.12 & $(-0.09,-.17)$ & -0.06 & $(-0.02,-0.09)$ & Partial mediation & $(-0.02,-0.09)$ \\
\hline Extravers $\rightarrow$ & Academic Stress Symptoms & -0.20 & $(-0.24,-0.15)$ & -0.10 & $(-0.06,-0.13)$ & -0.10 & $(-0.07,-0.14)$ & Partial mediation & $(-0.07,-0.14)$ \\
\hline Resilience & Academic Stress Factors & -0.13 & $(-0.17,-0.10)$ & -0.13 & $(-0.17,-0.10)$ & 0.00 & $(-0.04,0.05)$ & Direct only & $(-0.17,-0.10)$ \\
\hline Resilience & Academic Stress Symptoms & -0.07 & $(-0.11,-0.05$ & 0.00 & $(-0.04,0.04$ & -0.07 & $(-0.11,-0.05$ & $\begin{array}{l}\text { Full mediation } \\
\text { (suppression) }\end{array}$ & $(-0.11,-0.05)$ \\
\hline \multicolumn{10}{|l|}{ Model 3 (0) } \\
\hline Open Exp $\rightarrow$ & Resilience & -0.32 & $(-0.36,-0.31)$ & -0.32 & $(-0.36,-0.31)$ & 0.00 & $(-0.05,0.04)$ & Direct only & $(-0.36,-0.31)$ \\
\hline Open Exp $\rightarrow$ & Academic Stress Factors & -0.23 & $(-0.26,-0.20)$ & -0.18 & $(-0.23,-15)$ & -0.47 & $(-0.49,-0.44)$ & Partial mediation & $(-0.49,-0.44)$ \\
\hline Open Exp $\rightarrow$ & Academic Stress Symptoms & -0.20 & $(-0.24,-0.16)$ & -0.06 & $(-0.02,-0.10)$ & -0.13 & $(-0.16,-0.11)$ & Partial mediation & $(-0.16,-0.11)$ \\
\hline Resilience & Academic Stress Factors & -0.14 & $(-0.19,-0.11)$ & -0.14 & $(-0.18,-10)$ & 0.00 & $(-0.03,0.03)$ & Direct only & $(-0.18,-10)$ \\
\hline Resilience & Academic Stress Symptoms & 0.00 & $(-0.03,04)$ & 0.00 & $(-0.03,04)$ & 0.08 & $(-0.05,-11)$ & Partial mediation & $(-0.05,-11)$ \\
\hline \multicolumn{10}{|l|}{ Model 4 (A) } \\
\hline Agreeability $\rightarrow$ & Resilience & 0.38 & $(0.40,0.35)$ & 0.38 & $(0.40,0.35)$ & 0.00 & $(-0.04,0.05)$ & Direct only & $(0.40,0.35)$ \\
\hline Agreeability $\rightarrow$ & Academic Stress Factors & -0.08 & $(-0.12,-0.04)$ & -0.00 & $(-0.04,03)$ & -0.07 & $(-0.12,-0.04)$ & Full mediation & $(-0.12,-0.04)$ \\
\hline Agreeability $\rightarrow$ & Academic Stress Symptoms & -0.18 & $(-0.22,-0.15)$ & -0.13 & $(-0.18,-0.12)$ & -0.04 & $(-0.07,-0.01)$ & Partial mediation & $(-0.07,-0.01)$ \\
\hline Resilience & Academic Stress Factors & -0.20 & $(-0.25,-0.15)$ & -0.20 & $(-0.25,-0.15)$ & 0.00 & $(-0.03,0.03)$ & Direct only & $(-0.25,-0.15)$ \\
\hline Resilience & Academic Stress Symptoms & -0.12 & $(-0.16,-0.08)$ & 0.00 & $(-0.04,0.03)$ & -0.12 & $(-0.15,-0.09)$ & $\begin{array}{l}\text { Full mediation } \\
\text { (suppression) }\end{array}$ & $(-0.15,-0.09)$ \\
\hline \multicolumn{10}{|l|}{ Model 5 (N) } \\
\hline Neuroticism $\rightarrow$ & Resilience & -0.27 & $(-0.30,-0.24)$ & -0.27 & $(-0.30,-0.24)$ & 0.00 & $(-0.02,0.02)$ & Direct only & $(-0.30,-0.24)$ \\
\hline Neuroticism $\rightarrow$ & Academic Stress Factors & 0.44 & $(0.48,0.40)$ & 0.41 & $(0.48,0.40)$ & 0.02 & $(-0.03,0.04)$ & Direct only & $(0.48,0.40)$ \\
\hline Neuroticism $\rightarrow$ & Academic Stress Symptoms & 0.57 & $(0.60,0.53)$ & 0.34 & $(0.37,0.31)$ & 0.18 & $(0.15,0.22)$ & Partial mediation & $15,0.22)$ \\
\hline Resilience $\rightarrow$ & Academic Stress Factors & -0.08 & $(-0.11,-0.3)$ & -0.08 & $(-0.11,-0.3$ & 0.00 & $(-0.03,0.03)$ & Direct only & $(-0.11,-0.3)$ \\
\hline Resilience $\rightarrow$ & Academic Stress Symptoms & -0.03 & $(-0.07,0.02)$ & 0.00 & $(-0.03,0.03)$ & -0.03 & $(-0.07,0.02)$ & $\begin{array}{l}\text { Full mediation } \\
\text { (suppression) }\end{array}$ & $(-0.07,0.02)$ \\
\hline
\end{tabular}

Bootstrapping sample size $=405 . \mathrm{Cl}$, confidence interval. 
between extraversion and resilience suggests the advantages of positive emotional styles. The capacity for social interaction, close interpersonal relationships, and positive emotions have been found to enable persons to rebound subjectively and physiologically from stressful events (127). Extraversion behavior is positively related to resilience, which in turn facilitates the experience of positive emotions, and encourages seeking out other people and establishing relationships, creating strong social protection networks, which is a critical supportive factor during stressful times. Conscientious students have high self-efficacy and use problem-solving strategies that enhance coping with stressful situations $(66,74)$. Our results are similar to others because $\mathrm{N}$ shows a negative relationship with resilience $(19,84$, $85,128)$. Consequently, our study contributes toward specifying the non-regulatory and dysregulatory value of the remaining BF components.

The second hypothesis, that the proactive and reactive factors of resilience would differentially predict academic stress factors and symptoms, was confirmed. In this case, our evidence represents a valuable contribution in agreement with other previous studies $(28,93)$, by showing that resilience includes behavioral components that help to endure the negative event (factors that are more reactive in nature) as well as behaviors that help to overcome it (proactive factors, more regulatory in nature). The predictive value of the proactive factors consistently point in this direction, in agreement with prior research (68).

The third hypothesis, which stated that the stress factors pertaining to the teaching-learning process would be significant, positive predictors of students' stress symptoms, was also fulfilled. This result is also important, because it confirms that the University teaching-learning context acts as a stress trigger. In line with the previous investigation, stress factors in learning, in their own right, are predictors of students' stress symptoms (129).

The fourth hypothesis, regarding the existence of a general structional prediction model, was also acceptably confirmed. Our hypothesis predicted that the personality factors (C, E, O, A, N), in conjunction with resilience, would be diferential predictors of stress symptoms. The negative personality factor $(\mathrm{N})$, jointly with low Resilience, would positively predict stress factors and symptoms, just as this study has confirmed. This general predictive model served to confirm the general relationships between these constructs.

The fifth hypothesis, regarding the existence of specific, differential mediational models for each BF factor, was also acceptable. Previous research has already established a clear connection between conscientiousness, extraversion and selfregulation $(10,16,17)$. Students may be able to develop their self-regulation skills as a means to better management of their mental health and well-being. This research study has shown a significant mediational effect, the buffering effect of resilience, on the different components of the BF model, in predicting factors and symptoms of University stress. As shown in previous evidence, the greatest predictive power in regard to resilience came from factors $\mathrm{C}$ and $\mathrm{N}$, which were positive and negative predictors, respectively (30). In Shi's study, resilience significantly mediated the association of $\mathrm{C}, \mathrm{A}$ and $\mathrm{O}$, with anxiety symptoms. High levels of $\mathrm{A}, \mathrm{C}$ and $\mathrm{O}$ were associated with high levels of resilience and a lower level of anxiety symptoms. On the other hand, high $\mathrm{N}$, associated with low resilience, correlated to high levels of anxiety. This research, as well as our own, shows that BF factors are not only related directly to states of anxiety and stress, but indirectly through resilience. These results imply that intervention strategies for reducing stress at University should focus on the protective role of certain personality dimensions and in cultivating resilience in students.

\section{Conclusion}

The experience of stress in the University context, due to the difficulty of meeting the demands and requirements of study, is an important phenomenon that has captured the interest of researchers (16). It is important to reduce the impact of stress triggers and encourage students' ability to manage stress. This is essential to their progress, adaptation and success in the University context (130).

The clusters of regulatory BF factors $(\mathrm{C}, \mathrm{E})$, non-regulatory factors $(\mathrm{O}, \mathrm{A})$ and a dysregulatory factor $(\mathrm{N})$, along with proactive and reactive resilience factors, may act as a buffer that helps maintain higher levels of well-being, despite students' elevated levels of perceived stress and impaired mental health functioning (30). Self-regulation has also been linked to good adjustment (e.g., lower psychopathological symptoms) in students of higher education (131).

\section{Limitations}

Several study limitations disadvise broad generalization of these findings. The population in our sample is quite specific and may not be representative of a wider population. Moreover, the sample contained exclusively female students, given that previous research has shown gender differences in these variables (132). By focusing on personality dimensions and their relation to resilience, our study only considered factors and motivations that are internal to the individual. In future studies of resilience, characteristics of the environment and situational factors could be addressed, for example, social support and control over the study environment. The present study, despite certain limitations, contributes to our growing understanding of resilience, as represented in the literature from positive psychology and behavior $(19,133)$.

Students' stress depends not only on the stressors themselves, but also the synergy between these and students' personal approaches to coping with the situation wherein stress is generated (134). It is important to treat stress at the personal, social and institutional levels.

\section{Practical Implications for Counseling in the University Context}

There are evident implications for educational psychology and counseling in the University setting. Based on the present findings and those of previous research, the BF factors and resilience play an important role in students' levels of stress (10). Certain components of the $\mathrm{BF}$ model $(\mathrm{C}, \mathrm{E})$ are significantly related to resilience and protect against stress, while others $(\mathrm{N})$ prompt greater vulnerability to stressful situations. 
Intervention strategies that focus both on personality traits and on resilience should be implemented in the University context (19). Addressing these variables may be one way to reduce the stress experienced by students -both its prevalence and intensity (81). It is of great importance to detect and address at-risk students-those who have negative affective styles, difficulties in social interaction and who present deficits in selfregulation, self-control, or self-discipline $(135,136)$.

Education and Health professionals should seek to assess $\mathrm{BF}$ factors and resilience, and use intervention programs to further develop resilience in students $(19,66)$. Guidance services, student mentors, and lecturers can help students to engage in self-awareness about their personality profile and capacity to bounce back (137), in order to strengthen their understanding of their own personal resources for coping with stressful learning environments (138). For instance, they can pursue teaching methods that promote mindfulness (139) and students' cognitive activation [e.g., (140)], or offer other therapeutic or educational approaches. Many universities are already implementing support and intervention in stress management, built around the core concept of resilience $(130,141)$. The University of Edinburgh (142) offers a Student Resilience model; its declaration of intent states that Resilience "is both a key graduate attribute and an integral part of any transitions framework as it enables students to better cope with the challenges that they will encounter on their unique learning journey." Likewise, a team from three Australian universities [Curtin University, Queensland University, and University of South Australia; see (143)] have presented a project entitled Building Graduate Resilience for the disrupted future of the twenty-first Century, with the purpose of enhancing resilience in the context of stress in higher education (Project website: www.enhancingresilience.com).

Previous research has indicated that the transition and adjustment to University could be better understood as a

\section{REFERENCES}

1. Sarrionandia A, Ramos-Díaz E, Fernández-Lasarte O. Resilience as a mediator of emotional intelligence and perceived stress: a cross-country study. Front Psychol. (2018) 9:2653. doi: 10.3389/fpsyg.2018.02653

2. Côté JE. The Enduring Usefulness of Erikson's Concept of the Identity Crisis in the 21st Century: An Analysis of Student Mental Health Concerns. Identity. (2018) 18:1-13. doi: 10.1080/15283488.2018.1524328

3. Denovan A, Macaskill A. An interpretive phenomenological analysis of stress and coping in first year undergraduates. Br Educ Res J. (2013) 39:100224. doi: 10.1002/berj.3019

4. Hartley MT. Examining the relationships between resilience, mental health, and academic persistence in undergraduate college students. J Am Coll Health. (2011) 59:596-604. doi: 10.1080/07448481.2010. 515632

5. Rickwood D, Telford N, O'Sullivan Sh, Crisp D, Magyar R. National Tertiary Student Wellbeing Survey 2016. National Youth Mental Health Foundation Headspace, University of Canberra (2016). Available online at: https:// headspace.org.au/assets/Uploads/headspace-NUS-Publication-Digital.pdf (accessed July 21, 2020).

6. Pereira St, Reary K, Bottell J, Walker L, Dzikiti Ch. University Student Mental Health Survey 2018. A Large Scale Study into the Prevalence of Student Mental Illness Within UK Universities. (2019). The Insight Network. trajectory of risk and resilience. The first 2 years can be seen as a challenge, and the final years as an opportunity for growth and recovery (46). Such findings suggest that the first 2 years represent an important transition period where stress management and resilience programs can be highly applicable.

\section{DATA AVAILABILITY STATEMENT}

The raw data supporting the conclusions of this article will be made available by the authors, without undue reservation.

\section{ETHICS STATEMENT}

The studies involving human participants were reviewed and approved by http://www.estres.investigacion-psicopedagogica. org/lib/pdf/CERTIFICADO_COMITE_DE_ETICA_UNAV.

pdf. The patients/participants provided their written informed consent to participate in this study.

\section{AUTHOR CONTRIBUTIONS}

JF and JM-V: project managers, design, data analysis, and initial writing. MG-T and RA-G: bibliographic and manuscript review. MV-M and FP-S: data collection. All authors contributed to the article and approved the submitted version.

\section{FUNDING}

This study was supported by R\&D Project PGC2018-094672-BI00, University of Navarra, Ministry of Education and Science (Spain), and the European Social Fund (EU); R\&D Project UAL18- SEJ-DO31-A-FEDER. University of Almería (Spain), and the European Social Fund (EU).

7. Bedaso A, Duko B, Yeneabat T. Predictors of mental distress among undergraduate health science students of Hawassa University, College of Medicine and Health Sciences, Hawassa, SNNPR, Ethiopia: a cross-sectional study. Ann Gen Psychiatry. (2020) 19:6-11. doi: 10.1186/s12991-0200258-y

8. Farrer LM, Gulliver A, Bennett K, Fassnacht DB, Griffiths KM. Demographic and psychosocial predictors of major depression and generalised anxiety disorder in Australian university students. BMC Psychiatry. (2016) 16:1-9. doi: 10.1186/s12888-016-0961-z

9. Denovan A, Dagnalla N, Dhingrab K, Grogana S. Evaluating the Perceived Stress Scale among UK University students: implications for stress measurement and management. Stud Higher Educ. (2019) 44:12033. doi: 10.1080/03075079.2017.1340445

10. Durand-Bush N, McNeill K, Harding $\mathrm{M}$, Dobransky J. Investigating stress, psychological well-being, mental health functioning, and selfregulation capacity among university undergraduate students: Is this population optimally functioning? Canad J Couns Psychother. (2015) 49:25374. Retrieved from: https://cjc-rcc.ucalgary.ca/article/view/61066 (accessed August 02, 2020).

11. Oswalt SB, Lederer AM, Chestnut-Steich K, Day C, Halbritter A, Ortiz D. Trends in college students' mental health diagnoses and utilization of services, 2009-2015. J Am Coll Health. (2020) 68:4151. doi: $10.1080 / 07448481.2018 .1515748$ 
12. Reddy KJ, Menon KR, Thattil A. Academic stress and its sources among university students. Biomed Pharmacol J. (2018) 11:531-7. doi: $10.13005 / \mathrm{bpj} / 1404$

13. de Heer S. The Relationship Between Perceived Stress and Depressive Symptoms among Dutch university students moderated by personality traits? (Doctoral dissertation), Jans Universiteit Leiden, Institute of Psychology, EZ Leiden (2017). Retrieved from: https://scholarlypublications. universiteitleiden.nl/handle/1887/54855 (accessed July 22, 2020).

14. Saleh D, Camart N, Romo L. Predictors of stress in college students. Psychol Res. (2017) 7:42-9. doi: 10.3389/fpsyg.2017.00019

15. Lazarus RF, Folkman SCS. Stress, Appraisal and Coping. Ney York, NY: Springer Publishing Company (1984).

16. de la Fuente J, Amate J, González-Torres MC, Artuch R, García-Torrecillas $\mathrm{JM}$, et al. Effects of levels of self-regulation and regulatory teaching on strategies for coping with academic stress in undergraduate students. Front Psychol. (2020) 11:22. doi: 10.3389/fpsyg.2020.00022

17. de la Fuente J, Peralta-Sánchez FJ, Martínez-Vicente JM, Sander P, GarzónUmerenkova A, Zapata L. Effects of self-regulation vs. external regulation on the factors and symptoms of academic stress in undergraduate students. Front Psychol. (2020) 11:1773. doi: 10.3389/fpsyg.2020.01773

18. Vollrath M. Personality and hassles among University students: a three-year longitudinal study. Eur J Pers. (2000) 14:199215. doi: 10.1002/1099-0984(200005/06)14:3<199::AID-PER372>3.0.CO;2B

19. Backmann J, Weiss M, Schippers MC, Martin Hoegl, M. Personality factors, student resiliency, and the moderating role of achievement values in study progress. Learn Individ Diff. (2019) 72:39-48. doi: 10.1016/j.lindif.2019.04.004

20. Kankaraš M. Personality Matters: Relevance and Assessment of Personality Characteristics. OECD Education Working Papers, No. 157. Paris: OECD Publishing (2017). doi: 10.1787/8a294376-en

21. Eley DS, Leung J, Hong BA, Cloninger KM, Cloninger CR. Identifying the dominant personality profiles in medical students: implications for their well-being and resilience. PLoS ONE. (2016) 11:e0160028. doi: 10.1371/journal.pone.0160028

22. González-Torres MC, Artuch-Garde R. Resilience and coping strategy profiles at University: Contextual and demographic variables. Electron J Res Educ Psychol. (2014) 12:621-48. doi: 10.14204/ejrep.34.14032

23. Zhou K. Non-cognitive Skills: Definitions, Measurement and Malleability. Global Education Monitoring Report. UNESCO (2016).

24. Gray P. Declining Student Resilience: A Serious Problem for Colleges. Psychology Today (2015). Available online at: https://www.psychologytoday. com/intl/blog/freedom-learn/201509/declining-student-resilience-seriousproblem-colleges (accessed July 21, 2020).

25. Gray G, McGuinness C, Owende P. Non-cognitive factors of learning as early indicators of students at-risk of failing in tertiary education. In: Khine MS, Areepattamannil S, editors. Non-cognitive Skills and Factors in Educational Attainment. Dordrecht: Sense Publishers (2016). p. 199-239.

26. Ingram RE, Luxton DD. Vulnerability-stress models. In: Hankin BL, Abela JRZ, editors. Development of Psychopathology: A Vulnerability-Stress Perspective. Sage Publications, Inc. (2005). p. 32-46.

27. Stoffel JM, Cain J. Review of grit and resilience literature within health professions education. Am J Pharm Educ. (2018) 82:6150. doi: 10.5688/ajpe6150

28. Sahi M, Raghavi M. A study of personality in relation to resilience and stress. Int Educ Res. (2016) 4:10-8. doi: 10.31686/ijier.vol4.iss2.511

29. McDonnell S, Semkovska M. Resilience as mediator between extraversion, neuroticism, and depressive symptoms in University students. J Posit Psychol Wellbeing. (2020) 4:1-16. Retrieved from: https://journalppw.com/index. php/JPPW/article/view/164

30. Shi M, Liu L, Wang ZY, Wang L. The mediating role of resilience in the relationship between big five personality and anxiety among Chinese medical students: a cross-sectional study. PLOS ONE. (2015) 10:e0119916. doi: 10.1371/journal.pone.0119916

31. Biggs A, Brough P, Drummond S. Lazarus and Folkman's psychological stress and coping theory. In: The Handbook of Stress and Health: A Guide to Research and Practice. (2017). p. 351-64. New Jersey, NJ: John Wiley \& Sons Ltd. doi: 10.1002/9781118993811
32. de la Fuente J. Big Five Questionnaire, BFQ-U. Adaptation for Young University Students. Almería: University of Almería. Manuscript pending publication (2014)

33. Freire C, Ferradás MM, Núñez JC, Valle A, Vallejo G. Eudaimonic well-being and coping with stress in University students: the mediating/moderating role of self-efficacy. Int $J$ Environ Res Public Health. (2018) 16:48. doi: 10.3390/ijerph16010048

34. Karaman MA, Lerma E, Cavazos Vela J, Watson JC. Predictors of academic stress among college students. J Coll Couns. (2019) 22:4155. doi: 10.1002/jocc. 12113

35. Cabanach R, Souto-Gestal A, Franco V. Escala de Estresores Académicos para la evaluación de los estresores académicos en estudiantes universitarios Academic Stressor Scale for the evaluation of academic stressors in University students. Revista Iberoamericana de Psicología y Salud. (2016) 7:41-50. doi: 10.1016/j.rips.2016.05.001

36. Cabanach R, Souto-Gestal A, Fernández-Cervantes. Perfiles de regulación emocional y estrés académico en estudiantes de fisioterapia Profiles of emotional regulation and academic stress in physiotherapy students. Eur J Educ Psychol. (2017) 10:57-61. doi: 10.1016/j.ejeps.2017.07.002

37. Cabanach R, Souto-Gestal A, González-Doniz L, Franco-Taboada V. Perfiles de afrontamiento y estrés académico en estudiantes universitarios Coping and academic stress profiles in University students. Revista de Investigación Educativa. (2018) 36:421-33. doi: 10.6018/rie.36.2.290901

38. Deane P, Song Y. Academic stress as a predictor of chronic stress in University students. Psicol Educ. (2014) 20:4752. doi: 10.1016/j.pse.2014.05.006

39. Bob MH, Popescu CA, Pîrlog R, Buzoianu AD. Personality factors associated with academic stress in first year medical students. Hum Vet Med (HVM) Bioflux. (2014) 6:40-4.

40. Fimian MJ, Fastenau PA, Tashner JH, Cross AH. The measure of classroom stress and burnout among gifted and talented students. Psychol Sch. (1989) 26:13953. doi: 10.1002/1520-6807(198904)26:2<139::AID-PITS2310260205>3. $0 . \mathrm{CO} ; 2-\mathrm{E}$

41. Garett R, Liu S, Young SD. A longitudinal analysis of stress among incoming college freshmen. J Am Coll Health. (2017) 65:331-8. doi: 10.1080/07448481.2017.1312413

42. de la Fuente J, Martínez-Vicente JM, Peralta-Sánchez FJ, GarzónUmerenkova A, Vera MM, Paoloni P. Applying the SRL vs. ERL theory to the knowledge of achievement emotions in undergraduate University students. Front Psychol. (2019) 10:2070. doi: 10.3389/fpsyg.2019.02070

43. Xin Y, Wu J, Yao Z, Guan Q, Aleman A, Luo L. The relationship between personality and the response to acute psychological stress. Sci Rep. (2017) 7:16906. doi: 10.1038/s41598-017-17053-2

44. González MT, Landero R. Confirmación de un modelo explicativo del estrés y de los síntomas psicosomáticos mediante ecuaciones estructurales Confirmation of an explanatory model of stress and psychosomatic symptoms using structural equations. Revista Panamericana de Salud Pública. (2008) 23:7-18. doi: 10.1590/S1020-49892008000100002

45. Seun-Fadipe CT, Mosaku KS. Sleep quality and psychological distress among undergraduate students of a Nigerian University. Sleep Health. (2017) 3:1904. doi: 10.1016/j.sleh.2017.02.004

46. Conley CS, Shapiro JB, Huguenel BM, Kirsch AC. Navigating the college years: developmental trajectories and gender differences in psychological functioning, cognitive-affective strategies, and social well-being. Emerg. Adulthood. (2020) 8:103-17. doi: 10.1177/2167696818791603

47. Hernandez AL, González-Escobar S, González NI, López-Fuentes A, Barcelata BE. Stress, self-efficacy, academic achievement and resilience in emerging adults. Electron J Res Educ Psychol. (2019) 17:129-48. http://ojs.ual.es/ojs/index.php/EJREP/article/viewFile/2226/ 2809 doi: 10.25115/ejrep.v17i47.2226 (accessed July 25, 2020).

48. Uchil HB. The effect of stress on students' performance. Stress Manag Prof Int J. (2017) 5:17-21.

49. Deb S, Banu PR, Thomas S, Vardhan V, Rao T. Khawaja N. Depression among Indian University students and its association with perceived University academic environment, living arrangements and personal issues. Asian J Psychiatry. (2016) 23:108-17. doi: 10.1016/j.ajp.2016. 07.010 
50. Gustems-Carnicer J, Calderon C, Batalla-Flores A, Esteban-Bara F. Role of coping responses in the relationship between perceived stress and psychological well-being in a sample of spanish educational teacher students. Psychol Rep. (2019) 122:380-97. doi: 10.1177/0033294118758904

51. Holinka C. Stress, emotional intelligence, and life satisfaction in college students. Coll Stud J. (2015) 49:300-11.

52. Kertechian SK. Conscientiousness as a key to success for academic achievement among French University students enrolled in management studies. Int J Manag Educ. (2018) 16:154-65. doi: 10.1016/j.ijme.2018.02.003

53. Kim LE, Poropat AE, McCann C. Conscientiousness in education: its conceptualization, assessment and utility. In: Lipnevich AA, Preckel FF, Roberts RD, editors. Psychosocial Skills and School Systems in the 21st Century. Theory, Research and Practice. New York, NY: Springer (2016). p. $155-79$.

54. Kandler C, Bleidorn W. Personality differences and development: genetic and environmental contributions. In: Wright JD, editor. International Encyclopedia od the Social and Behavioral Sciences. 2nd ed. New York, NY: Elsevier (2015). p. 884-90.

55. Funder DC. Personality. Ann Rev Psychol. (2001) 52:197221. doi: 10.1146/annurev.psych.52.1.197

56. Walton KE, Billera KA. Personality development during the school aged years: implications for theory, research and practice. In: Lipnevich AA, Preckel FF, Roberts RD, editors. Psychosocial Skills and School Systems in the 21st Century. Theory, Research and Practice. New York: NY: Springer (2016). p. 93-111.

57. Mattews G, Deary IJ, Whiteman. Personality Traits. 2nd ed. Cambridge: Cambridge University Press (2003).

58. Connor-Smith JK, Flachsbart C. Relations between personality and coping: a meta-analysis. J Pers Soc Psychol. (2007) 93:1080107. doi: 10.1037/0022-3514.93.6.1080

59. Komarraju M, Karau S, Schmeck RR. Role of the Big Five personality traits in predicting college students' academic motivation and achievement. Learn Indiv Diff. (2009) 19:47-52. doi: 10.1016/j.lindif.2008.07.001

60. Wang S, Zhao Y, Li J, Wang X, Luo K, Gong Q. Brain structure links trait conscientiousness to academic performance. Sci Rep. (2019) 9:12168. doi: 10.1038/s41598-019-48704-1

61. Schneider M, Preckel F. Variables associated with achievement in higher education: a systematic review of meta-analyses. Psychol Bull. (2017) 143:565-600. doi: 10.1037/bul0000098

62. Kokko K, Rantanen J, Pulkkinen L. Associations between mental well-being and personality from a life-span perspective. In: Blarny M, editor. Personality and Well-Being Across the Life Span. New York, NY: Palgrave Macmillan. (2015). p. 134-59.

63. Steel P, Schmidt J, Shultz J. Refining the relationship between personality and subjective well-being. Psychol Bull. (2008) 134:138-61. doi: 10.1037/0033-2909.134.1.138

64. Romer AL, Hariri AR, Strauman TJ. Regulatory focus and the $p$ factor: evidence for self-regulatory dysfunction as a transdiagnostic feature of general psychopathology. J Psychiatr Res. (2021) 137:17885. doi: 10.1016/j.jpsychires.2021.02.051

65. de la Fuente J. Theory of self- vs. externally-regulated learning tm: fundamentals, evidence, and applicability. Front Psychol. (2017) 8:1675. doi: 10.3389/fpsyg.2017.01675

66. de la Fuente J, Sander P, Martínez-Vicente JM, Vera M, Garzón A, Fadda S. Combined effect of levels in personal self-regulation and regulatory teaching on meta-cognitive, on meta-motivational, and on academic achievement variables in undergraduate students. Front Psychol. (2017) 8:232. doi: 10.3389/fpsyg.2017.00232

67. Pachón-Basallo M, de la Fuente J, González-Torres MC. Regulation/nonregulation/dys-regulation of health behavior, psychological reactance, and health of University undergraduate students. Int J Environ Res Public Health. (2021) 18:3793. doi: 10.3390/ijerph18073793

68. de la Fuente J, Paoloni P, Kauffman D, Yilmaz Soylu M, Sander P, Zapata L. Big five, self-regulation, and coping strategies as predictors of achievement emotions in undergraduate students. Int J Environ Res Public Health. (2020) 17:3602. doi: 10.3390/ijerph17103602
69. Zimmerman BJ. Attaining self-regulation: a social cognitive perspective. In: Boekaerts M, Pintrich PR, Zeidner M, editors. Handbook of Self-Regulation. San Diego, CA: Academic Press (2000). p. 13-40.

70. Prince-Embury S, Saklofske DH, Keefer KV. Three-factor model of personal resiliency. In: Kumar U, editor. Routledge International Handbooks. The Routledge International Handbook of Psychosocial Resilience. New York, NY: Routledge; Taylor and Francis Group (2017). p. 34-45.

71. Ryan J, Jones S, Hayes P, Turner M. Building student resilience for graduate work readiness. In Diver A, editor. Employability via Higher Education: Sustainabilility as Scholars. Liverpool: Springer. (2019). p. 135-54.

72. Turner M, Scott-Young CM, Holdsworth S. Promoting wellbeing at University: the role of resilience for students of the built environment. Constr Manag Econ. (2017) 35:707-18. doi: 10.1080/01446193.2017.1353698

73. Ayala JC, Manzano G. Academic performance of first-year University students: the influence of resilience and engagement. Higher Educ Res Dev. (2018) 37:1321-35. doi: 10.1080/07294360.2018.1502258

74. Artuch-Garde R, González-Torres MC, de la Fuente J, Vera MM, FernándezCabezas M, López-García M. Relationship between resilience and selfregulation: a study of Spanish youth at risk of social exclusion. Front Psychol. (2017) 8:612. doi: 10.3389/fpsyg.2017.00612

75. DeRosier ME, Frank E, Schwartz V, Leary KA. The potential role of resilience education for preventing mental health problems for college students. Psychiatr Ann. (2013) 43:538-44. doi: 10.3928/00485713-20131206-05

76. de la Fuente J, Santos FH, Garzón-Umerenkova A, Fadda S, Solinas G, Pignata S. Cross-sectional study of resilience, positivity and coping strategies as predictors of engagement-burnout in undergraduate students: implications for prevention and treatment in mental well-being. Front Psychiatry. (2021) 12:596453. doi: 10.3389/fpsyt.2021.596453

77. Grossman MR. Clarifying the Nature of Resilience: A Meta-Analytic Approach (Graduate theses and dissertations) (2014). http://scholarcommons.usf.edu/ etd/5031 (accessed July 25, 2020).

78. Oshio A, Taku K, Hirano M, Saeed G. Resilience and big five personality traits: a meta-analysis. Pers Indiv Diff. (2018) 127:5460. doi: 10.1016/j.paid.2018.01.048

79. de la Fuente J, Fernández-Cabezas M, Cambil M, Vera MM, GonzálezTorres MC, Artuch-Garde R. Linear relationship between resilience, learning approaches, and coping strategies to predict achievement in undergraduate students. Front Psychol. (2017) 8:1039. doi: 10.3389/fpsyg.2017.01039

80. Eley DS, Cloninger CR, Walters L, Laurence C, Synnott R, Wilkinson D. The relationship between resilience and personality traits in doctors: implications for enhancing well-being. PeerJ. (2013) 1:e216. doi: 10.7717/peerj.216

81. Campbell-Sills L, Cohan SL, Stein MB. Relationship of resilience to personality, coping, and psychiatric symptoms in young adults. Behav Res Ther. (2006) 44:585-99. doi: 10.1016/j.brat.2005.05.001

82. Dunn LB, Iglewicz A, Moutier, C. A conceptual model of medical student well-being: promoting resilience and preventing burnout. Acad Psychiatry. (2008) 32:44-53. doi: 10.1176/appi.ap.32.1.44

83. Fletcher D, Sarkar M. Psychological resilience: a review and critique of definitions, concepts, and theory. Eur Psychol. (2013) 18:12-23. doi: 10.1027/1016-9040/a000124

84. Balgiu BA. Self-esteem, personality and resilience. Study of a student emerging adults group. J Educ Sci Psychol. (2017) 7:93-9.

85. Ercan H. The relationship between resilience and the big five personality traits in emerging adulthood. Eur J Educ Res. (2017) 70:83-103. doi: 10.14689/ejer.2017.70.5

86. Fayombo G. The relationship between personality traits and psychological resilience among the Caribbean adolescents. Int J Psychol Stud. (2010) 2:105-16. doi: 10.5539/ijps.v2n2p105

87. Lu Y, Yang D, Niu Y, Zhang H, Du B, Jiang X. Factors associated with the resilience of Tibetan adolescent survivors five years after the 2010 Yushu earthquake. PLoS ONE. (2020) 15:e0231736. doi: 10.1371/journal.pone.0231736

88. Pendergast K. The Role of Resilience, Emotion Regulation, and Perceived Stress on College Academic Performance. (2017). Available online at: https:// scholar.utc.edu/cgi/viewcontent.cgi?referer=https://scholar.google.es/\& httpsredir=1\&article=1665\&context=theses (accessed July 25, 2020). 
89. Soliemanifar O, Soleymanifar A, Afrisham R. Relationship between personality and biological reactivity to stress: a review. Psychiatry Investig. (2018) 15:1110-4. doi: 10.30773/pi.2018.10.14.2

90. Ebstrup JF, Eplov LF, Pisinger C, Jørgensen T. Association between the Five Factor personality traits and perceived stress: is the effect mediated by general self-efficacy? Anxiety Stress Coping. (2011) 24:40719. doi: 10.1080/10615806.2010.540012

91. Shokri O, Kadivar P, Naghsh Z, Ghanai Z, Daneshvapour Z, Molaei M. Personality traits, academic stress, and academic performance. J Educ Psychol Stud. (2007) 3:25-48.

92. Pidgeon AE, Rowe NF, Stapleton P, Magyar HB, Lo BC. Examining characteristics of resilience among University students: an international study. Open J Soc Sci. (2014) 2:14-22. doi: 10.4236/jss.2014.211003

93. Pidgeon AM, Pickett L. Examining the differences between University students' levels of resilience on mindfulness, psychological distress and coping strategies. Eur Sci J (Special Edition). (2017) 13:10313. Retrieved from: http://eujournal.org/index.php/esj/article/view/9246 (accessed November 06, 2019).

94. Conley CS, Durlak JA, and Kirsch AC. A meta-analysis of universal mental health prevention programs for higher education students. Prevention Sci. (2015) 16:487-507. doi: 10.1007/s11121-015-0543-1

95. Conley CS, Kirsch AC, Dickson DA, and Bryant FB. Negotiating the transition to college: Developmental trajectories and gender differences in psychological functioning, cognitive affective strategies, and social well-being. Emerging Adulthood. (2014) 2:195-210. doi: $10.1177 / 2167696814521808$

96. Lecic-Tosevski D, Vukovic O, Stepanovic J. Stress and personality. Psychiatriki. (2011) 22:290-7.

97. Lü W, Wang Z, Liu Y, Zhang H. Resilience as a mediator between extraversion, neuroticism and happiness, PA and NA. Pers Indiv Diff. (2014) 63:128-33. doi: 10.1016/j.paid.2014.01.015

98. Carrasco MA, Holgado P, del Barrio, MV. Dimensionalidad del cuestionario de los cinco grandes (BFQ-N) en población Española [Dimensionality of the Big Five Questionnaire (BFQ-N) in Spanish population]. Psicothema. (2005) 17:286-91.

99. Barbaranelli C, Caprara GV, Rabasca A, Pastorelli C. A questionnaire for measuring the Big Five in late childhood. Pers Indiv Diff. (2003) 34:64564. doi: 10.1016/S0191-8869(02)00051-X

100. Connor KM, Davidson JR. Development of a new resilience scale: the Connors-Davidson resilience scale (CD-RISC). Depress Anxiety. (2003) 18:76-82. doi: 10.1002/da.10113

101. Mateu J, García-Renedo F, Caballer S, Gil-Beltrán J. Traducción \& adaptación del CD-RISC (Connor \& Davison, 2003). [Translation and adaptation of the CD-RISC (Connor \& Davison, 2003)]. University of Castellón (2010). Retrieved from: http://repositori.uji.es/xmlui/bitstream/ handle/10234/77669/forum_2009_15.Pdf (accessed December 02, 2018).

102. Manzano-García G, Ayala-Calvo JC. Psychometric properties of ConnorDavidson Resilience Scale in a spanish sample of entrepreneurs. Psicothema. (2013) 25:245-51. doi: 10.1037/t71949-000

103. Berry DM, York K. Depression and religiosity and/or spirituality in college: a longitudinal survey of students in the USA. Nurs Health Sci. (2011) 13:76-83. doi: 10.1111/j.1442-2018.2011.00584.x

104. Cabanach RG, Valle A, Rodríguez S, Piñeiro I. Variables explicativas del estrés en estudiantes universitarios: Construcción de una escala de medida Explanatory variables of stress in University students: Construction of a measurement scale. Comunicación V Congreso nternacional de Psicología y Educación: Los retos del futuro. Oviedo (2008). p. 23-5.

105. Cabanach RG, Arias AV, Martínez SR, Gerpe MG, De Alda PMR. Programa de intervención para mejorar la gestión de los recursos motivacionales en estudiantes universitarios. Revista española Pedagogía. (2007) 65:237-55.

106. de la Fuente J, López M, Zapata L, Sollinas G, Fadda S. Improving mental health through an online self-assessment and self-help e-utility in University students. In: Nata RV, editor. Progress in Education. New York, NY: Nova Publisher (2015). p. 63-74.

107. Lohr S. Sampling: Design and Analysis. Boston, MA: Cengage Learning (1999).

108. Tabachnick BG, Fidell LS. Principal components and factor analysis. Using Multivar Stat. (2001) 4:582-633.
109. Tabachnick BG, Fidell LS. Cleaning up your act: screening data prior to analysis. Using Multivar Stat. (2001) 5:61-116.

110. Weston R, Gore PAA. Brief guide to structural equation modeling. Couns Psychol. (2006) 34:719-51. doi: 10.1177/0011000006286345

111. Kline T. Psychological Testing: A Practical Approach to Design and Evaluation. (2005). Sage.

112. Mardia KV. Measures of multivariate skewness and kurtosis with applications. Biometrika. (1970) 57:519-30. doi: 10.1093/biomet/57.3.519

113. Ato M, Vallejo G. Los efectos de terceras variables en la investigación psicológica The effects of third variables in psychological research. Ann Psychol. (2011) 27:550-61.

114. Bentler PM. Comparative fit indexes in structural models. Psychol Bull. (1990) 107:238. doi: 10.1037/0033-2909.107.2.238

115. Ho R. Handbook of Univariate and Multivariate Data Analysis and Interpretation With SPSS. Baca Raton, FL: CRC Press (2006).

116. Keith TZ. Multiple Regression and Beyond. Boston, MA: Pearson Education, Inc. (2006).

117. Kenny D. Effect Size of the Indirect Effect. (2012). Available online at: Available online at: http://davidakenny.net/cm/mediate.htm (accessed July 21, 2020).

118. Grossman MR. The Structure of Resilience: An Empirical Examination of Resilience Factors. (Graduate theses and dissertations). University of South Florida, Florida (2017).

119. Tamannaeifar M, Shahmirzaei S. Prediction of academic resilience based on coping styles and personality traits. Pract Clin Psychol. (2019) 7:110. doi: $10.32598 /$ jpcp.7.1.1

120. Lomas T, Ivtzan I. Second wave positive psychology: exploring the positive-negative dialectics of wellbeing. J Happ Stud. (2016) 17:175368. doi: 10.1007/s10902-015-9668-y

121. Lyons ST, Schweitzer L, Ng ESW. Resilience in the modern career. Career Dev Int. (2015) 20:363-83. doi: 10.1108/CDI-02-2015-0024

122. Roghayeth $S$. The relationship between resilience and the Big Five personality factors. Knowl Res Appl Psychol. (2012) 13:95-102.

123. Zager-Kocjan G, Kavčič T, Avsec A. Resilience matters: explaining the association between personality and psychological functioning during the COVID-19 pandemic. Int J Clin Health Psychol. (2021) 21:100198. doi: 10.1016/j.ijchp.2020.08.002

124. Robinson MD. Cognitive approaches to personality. In: John OP, Robins WR, editors. Handbook of Personality: Theory and Research. Ney York, NY: The Guilford Press (2021). p. 369-84.

125. Sanchez-Ruiz MJ, El Khoury, J. A model of academic, personality, and emotion-related predictors of University academic performance. Front Psychol. (2019) 10:2435. doi: 10.3389/fpsyg.2019.02435

126. Tamannaeifar MR, Behzadmoghaddam R. Examination of the relationship between life satisfaction and perceived social support. Int Acad J Org Behav Hum Resour Manag. (2016) 3:8-15.

127. Tamannaeifar S, Gharaee B, Bakhshizade A, Sheybani F. The investigation of relationship between behavioral and decisional procrastination with personality characteristics among students of Tehran Universities. Int J Appl Behav Sci. (2016) 3:15-20. doi: 10.22037/ijabs.v3i2.13395

128. Nikčevića AV, Marino C, Kolubinskic DC, Marcantonio DL, Spadac M. Modelling the contribution of the Big Five personality traits, health anxiety, and COVID-19 psychological distress to generalised anxiety and depressive symptoms during the COVID-19 pandemic. J Affect Disord. (2021) 279:57884. doi: 10.1016/j.jad.2020.10.053

129. de la Fuente J, Pachón-Basallo, S.antos FH, Peralta-Sánchez FJ, GonzálezTorres MC, Artuch-Garde R, et al. How has the COVID-19 crisis affected the academic stress of University students? The role of teachers and students. Front Psychol. (2021) 12:626340. doi: 10.3389/fpsyg.2021.626340

130. Turner M, Simmons DR. Taking a partnered approach to managing academic stress: An undergraduate study. Int J Constr Educ Res. (2020) 16:251-69. doi: 10.1080/15578771.2019.1619637

131. Tarabochia DS. A comprehensive stress education and reduction program utilizing a well-being model: Incorporating the ASCA student standards. $J$ Sch Couns. (2013) 11:1-36.

132. Stefanovics EA, Edwards LM, Pietrzak RH. Personality and body mass index in US Military Veterans: results from the national health and resilience in veterans study. Psychiatr Q. (2021) 92:1-7. doi: 10.1007/s11126-020-09878-4 
133. van der Vegt G, Essens P, Wahlström M, George G. Managing risk and resilience. Acad Manag J. (2015) 58:971-80. doi: 10.5465/amj.2015.4004

134. Jain G, Singhai M. Academic stress among students: a review of literature. Prestige e-J Manag Res. (2017) 4:58-67.

135. Homberg JR, Jagiellowicz JA. neural model of vulnerability and resilience to stress-related disorders linked to differential susceptibility. Mol Psychiatry. (2021) 26:1-11. doi: 10.1038/s41380-021-01047-8

136. Johnson ML, Taasoobshirazi G, Kestler JL, Cordova J. Models and messengers of resilience: a theoretical model of college students' resilience, regulatory strategy use, and academic achievement. Educ Psychol. (2015) 35:869-85. doi: 10.1080/01443410.2014. 893560

137. Nijhuis J, Segers MR, Gijselaers W. The interplay of perceptions of the learning environment, personality and learning strategies. Stud Higher Educ. (2007) 32:59-77. doi: 10.1080/03075070601099457

138. Regehr C, Glancy D, Pitts A. Interventions to reduce stress in University students: a review and meta-analysis. J Affect Disord. (2013) 148:111. doi: 10.1016/j.jad.2012.11.026

139. Caldwell K, Harrison M, Adams M, Quin RH, Greeson J. Developing mindfulness in college students through movement-based courses: effects on self-regulatory self-efficacy, mood, stress, and sleep quality. J Am Coll Health. (2010) 58:433-42. doi: 10.1080/07448480903540481

140. Alivernini F, Manganelli S, Lucidi F. The last shall be the first: Competencies, equity and the power of resilience in the Italian school system. Learn Individ Diff. (2016) 51: 19-28. doi: 10.1016/j.lindif.2016.08.010
141. Burton NW, Pakenham KI, Brown WJ. Feasibility and effectiveness of psychosocial resilience training: a pilot study of the READY program. Psychol Health Med. (2010) 15:266-77. doi: 10.1080/135485010037 58710

142. University of Edinburgh. Building Student Resilience Model. (2016). Available online at: https://www.ed.ac.uk/institute-academic-development/ learning-teaching/staff/levels/academic-transitions-toolkit/buildingstudent-resilience-model (accessed July 25, 2020).

143. Brewer M, Barnard S, Van kessel G. Building Graduate Resilience for the Disrupted Future of the 21st Century. Final report of 2017 ATN Learning and Teaching Grant (2018). Available online at: https://www.atn.edu.au/ siteassets/industry-collaboration/2017-atn-learning-and-teaching-grantfinal-report-certified.pdf (accessed July 21, 2020).

Conflict of Interest: The authors declare that the research was conducted in the absence of any commercial or financial relationships that could be construed as a potential conflict of interest.

Copyright (C) 2021 de la Fuente, González-Torres, Artuch-Garde, Vera-Martínez, Martínez-Vicente and Peralta-Sánchez. This is an open-access article distributed under the terms of the Creative Commons Attribution License (CC BY). The use, distribution or reproduction in other forums is permitted, provided the original author(s) and the copyright owner(s) are credited and that the original publication in this journal is cited, in accordance with accepted academic practice. No use, distribution or reproduction is permitted which does not comply with these terms. 